NBER WORKING PAPER SERIES

\title{
WATER TREATMENT AND CHILD MORTALITY: EVIDENCE FROM KENYA
}

\author{
Johannes Haushofer \\ Michael Kremer \\ Ricardo Maertens \\ Brandon Joel Tan
}

Working Paper 29447

http://www.nber.org/papers/w29447

\author{
NATIONAL BUREAU OF ECONOMIC RESEARCH \\ 1050 Massachusetts Avenue \\ Cambridge, MA 02138 \\ November 2021
}

We thank Anett John and Kate Orkin for sharing their data with us. We also thank Clair Null for sharing her data on the Kenya WASH Benefits study. We thank Kanika Bahl and Amrita Ahuja for helpful comments and suggestions. All errors are our own. We thank the Dioraphte Foundation, the National Institutes of Health, and Sint Antonius Stichting for funding. Johannes Haushofer, Stockholm University, Department of Economics; IFN; MPI Bonn; and NBER (johannes.haushofer@ne.su.se). Michael Kremer, Department of Economics, University of Chicago; and NBER (kremermr@uchicago.edu). Ricardo Maertens, Amazon (ricardo.maertens@gmail.com), contributed to this research paper prior to joining Amazon. Brandon Tan, Department of Economics, Harvard University (btan@g.harvard.edu). The views expressed herein are those of the authors and do not necessarily reflect the views of the National Bureau of Economic Research.

At least one co-author has disclosed additional relationships of potential relevance for this research. Further information is available online at http://www.nber.org/papers/w29447.ack

NBER working papers are circulated for discussion and comment purposes. They have not been peer-reviewed or been subject to the review by the NBER Board of Directors that accompanies official NBER publications.

(C) 2021 by Johannes Haushofer, Michael Kremer, Ricardo Maertens, and Brandon Joel Tan. All rights reserved. Short sections of text, not to exceed two paragraphs, may be quoted without explicit permission provided that full credit, including $\odot$ notice, is given to the source. 
Water Treatment and Child Mortality: Evidence from Kenya

Johannes Haushofer, Michael Kremer, Ricardo Maertens, and Brandon Joel Tan

NBER Working Paper No. 29447

November 2021

JEL No. I15,O1

\begin{abstract}
$\underline{\text { ABSTRACT }}$
Each year, around 500,000 children under 5 die from diarrhea, making it the third-leading cause of death in this age group. More than 80 percent of these deaths are attributable to unsafe drinking water. Drinking water can be made safe through dilute chlorine solution, but take-up of this technology has been low. Previous work has shown that free community-wide provision of dilute chlorine solution through "dispensers" - reservoirs of chlorine solution at water sources that make chlorination easy and free - increases take-up of chlorination. However, it has remained unclear whether this increase also translates into reduced mortality. Here we show that four years of community-wide provision of dilute chlorine solution in rural Kenya reduces allcause under-5 mortality by 1.4 percentage points (95\% CI: $0.3 \mathrm{pp}, 2.5 \mathrm{pp}$ ), a $63 \%$ reduction relative to control. We estimate that at USD 25 per DALY averted, free provision of chlorine solution is twenty times more cost-effective than the WHO "highly cost-effective" threshold.
\end{abstract}

Johannes Haushofer

Department of Economics

Stockholm University

Universitetsvägen $10 \mathrm{~A}$

Stockholm 10691 Sweden

and Max Planck Institute for Collective Goods, Bonn, Germany

and Institute for Industrial Economics,

Stockholm, Sweden

and also NBERÂ

johannes.haushofer@ne.su.se

Michael Kremer

University of Chicago

Kenneth C. Griffin Department of Economics

1126 E. 59th St.

Chicago, IL 60637

and NBER

kremermr@uchicago.edu
Ricardo Maertens

Amazon

515 Westlake Ave N

Seattle, WA 98109

ricardo.maertens@gmail.com

Brandon Joel Tan

Department of Economics

Harvard University Littauer

Center G27

1805 Cambridge Street

Cambridge, MA 02138

btan@g.harvard.edu 


\section{Introduction}

Diarrhea is the third leading cause of death among children under 5, accounting for 500,000 deaths in 2017 (Global Burden of Disease Collaborative Network, 2018). More than 80 percent of these deaths are attributable to contaminated drinking water. Chlorination has been shown to be not only safe and inexpensive, but also effective in inactivating most pathogens that cause diarrhea (CDC, 2014a). Recent studies have shown that free provision of dilute chlorine solution can dramatically increase usage of this technology: Kremer et. al (2009) find in a randomized experiment that the free distribution of chlorine solution raises the usage rate to $60 \%$, from a baseline of $10 \%$ when the solution is sold at $\$ 0.3$ per month. In another randomized experiment, Dupas et. al (2016) find that free provision increases chlorine use by 60 percentage points relative to when a price is charged.

But does the free provision of chlorine also reduce mortality? Non-experimental evidence suggests that the provision of clean water effectively reduces child mortality by 25 to $50 \%$ (Cutler and Miller, 2005; Galiani et al., 2005; Balhotra et al., 2017; Alsan and Goldin, 2019). However, there is scant randomized control trial (RCT) evidence because adequately powered studies to detect effects of child survival would require very large sample sizes and correspondingly large costs. In addition, Ashraf et al. (2010) argue that selection on charging fees for the use of chlorine screens out those people that would be less likely to use the product in their drinking water, possibly reducing the average child survival effect when provision is free. Thus, water treatment is typically excluded from the list of evidence-backed child survival interventions endorsed by organizations such as UNICEF, the WHO, and the World Bank.

In this paper, we exploit random variation in free community-wide provision of chlorine to study its effect on child mortality. We use random assignment of villages to treatment and control conditions from the Kenya WASH Benefits (WASH-B) study (Null et al., 2018), an RCT that examined the effects of free water chlorination on early childhood development.

In the treatment villages, the study provided free dilute chlorine solution in two ways: through provision of dilute chlorine solution (WaterGuard) to households with children for one year; and through point-of-collection chlorine dispensers, which the "Dispensers for Safe Water" (DSW) program by the NGO Evidence Action maintained after the end of the WASH-B study. The dispensers make chlorination convenient, salient, and public, thereby potentially removing several obstacles to chlorination at once.

We study children born in villages randomly assigned to a water treatment and a control group. We use data collected by John \& Orkin (2018) four to five years after the rollout of the intervention on a sample of children born to mothers not enrolled in WASH-B, over twice as large as than analyzed in the original study (Null et al., 2018). Households in control villages still had access to chlorine in shops and kiosks, but did not receive it for free in the household or through dispensers.

Comparison of post-intervention mortality risks between treatment and control areas using an ANCOVA analysis (i.e. controlling for baseline mortality risks) suggests that the communitywide provision of dilute chlorine solution through dispensers and WaterGuard reduced all-cause under-5 mortality by 1.41 p.p. (95\% CI: 0.27 p.p., 2.55 p.p.), a $63 \%$ reduction relative to control, four years after the start of the intervention. A difference-in-difference analysis produces similar results. Under- 2 mortality was reduced by 1.36 p.p. (95\% CI: 0.18 p.p., 2.54 p.p.), or $67 \%$ CI relative to control. We obtain quantitatively similar effects if we restrict the analysis to the time period where chlorine was freely provided only through dispensers (using data from after the first 
year of the intervention where WaterGuard was also given), suggesting that dispensers alone have similar effects, while also being more cost-effective.

Using detailed cost and take-up data from Evidence Action, our analysis suggests that free point-of-collection chlorine dispenser systems are highly cost-effective to operate at scale. Based on our estimates of the effect of the community-wide provision of dilute chlorine solution on under-5 mortality (-1.41 p.p.), we estimate that the cost of Evidence Action's operations is USD 1,941 per death averted. This suggests that the provision of chlorine through Evidence Action's DSW program, at USD 25 per DALY averted, is much more cost-effective than the threshold suggested by the WHO to determine if interventions are "highly cost-effective" (WHO, 2014).

An important puzzle about the impacts we report here is why they are so large. A recent meta-analysis finds a mortality reduction through dilute chlorine provision of $25.4 \%$ in other studies, compared to $63 \%$ in this study (Kremer et al., 2020). However, it is important to note that the meta-analytic average lies within the confidence interval of our estimate. Another possible reason for this discrepancy is that our study area had higher rates of water contamination and diarrhea than others. However, within our area, we do not observe larger treatment effects in districts with worse baseline outcomes than in others. Nevertheless, it is possible that the region, or parts of it, were exposed to negative health shocks after baseline that increased our treatment effects. In line with this view, the treatment effect is concentrated in one of several districts in the sample. Finally, dispensers may generate larger treatment effects if they engender more consistent levels of water treatment than other interventions. Testing consistency of use, rather than levels, is therefore an important area for future study.

The remainder of this paper is organized as follows. Section 2 provides some background information on (i) child mortality, diarrhea, and chlorine, (ii) breastfeeding practices in our study areas, (iii) the design of the Kenya WASH-B intervention, and (iv) the chlorine dispenser system. Section 3 describes the data collected by John \& Orkin (2018) that we use to estimate effects on child mortality. The statistical analysis is presented in Section 4, and the results are presented in Section 5. Section 6 presents a cost-effectiveness analysis of the community-wide provision of dilute chlorine solution. Section 7 concludes and discusses limitations.

\section{Background}

This section first provides background information on child mortality, diarrhea, and the health effects of water chlorination. Second, we provide descriptive statistics on mortality and breastfeeding practices in the study areas. Third, we provide some background information on dispensers. Fourth, we describe the experimental design of the Kenya WASH-B study.

\subsection{Child mortality, diarrhea, and water chlorination}

Diarrhea is one of the leading causes of child mortality. Because chlorine effectively inactivates most pathogens that cause diarrhea (CDC, 2014a), water chlorination can reduce child diarrhea. Recent meta-analyses (Clasen et al. 2015, Wolf et al. 2018) have found that water chlorination significantly reduces diarrhea risk among children under 5 . However, concerns about reporting bias with caregiver-reported diarrhea (more details in Section 6) have caused some to question the validity of many existing RCTs examining the impact of water chlorination (and other water treatments) on child diarrhea and to call either for blinded studies or for measurement of objective outcomes (Schmidt and Cairncross, 2009).

At least since the early twentieth century, it has been hypothesized that the number of deaths averted by water treatment (e.g. chlorination) also encompasses deaths from diseases other 
than diarrhea. This hypothesis is known as the Mills-Reincke phenomenon. ${ }^{2}$ Sedgwick and Macnutt (1910) estimate that after the introduction of water treatment in Hamburg in the late nineteenth century, for every death from diarrhea and gastrointestinal disease averted, there were 5.3 fewer deaths from other causes. Therefore, by reducing the risk of diarrheal disease, water treatment can avert deaths from both diarrheal and non-diarrheal infectious diseases. More recent epidemiological studies have shown evidence of an association between diarrheal episodes and an increased risk of acute lower respiratory infection (ALRI) among children in Ghana, Nepal, India, and Israel (Schmidt et al., 2009; Coles et al., 2005; Walker et al., 2013b). ${ }^{3}$ Additionally, water treatment can reduce neo-natal $(<1$ month) mortality via cleaner births and postnatal care practices, improved maternal health, and disproportionately prevent severe diarrhea cases which all have implications for mortality.

Non-experimental studies suggest strong impacts of water treatment on child mortality. Cutler and Miller (2005) find that water chlorination and filtration across 13 US cities accounted for $50 \%$ of the decline in infant mortality from 1900 to 1936 . Similar results have been observed for water connection and treatment reforms in Argentina (Galiani et al., 2005), Mexico (Balhotra et al., 2017), and the Boston area (Alsan and Goldin, 2019). However, policy makers in public health are skeptical of the non-experimental nature of these results. We provide new experimental evidence supporting this literature with estimates of similar magnitudes.

There is scant RCT evidence of the child mortality effects of water treatment in general, and of chlorination in particular. Because examining mortality requires large sample sizes and thus budgets, RCTs on water treatment are typically only powered to detect effects on intermediate outcomes (e.g., diarrhea) rather than mortality. To our knowledge, Crump et al. (2005) is the only study which finds significant effects on child survival, despite being designed to detect outcomes on diarrhea. The study, also in Western Kenya, found a $42 \%$ reduction in under- 2 mortality after pooling effects from a flocculant-disinfectant and a hypochlorite intervention. A companion metaanalysis combines all the existing RCT evidence of the mortality effects of water treatment evidence, increasing the power of the analysis to detect effects on mortality, and estimates that water chlorination significantly reduces child mortality by $32 \%$, a magnitude that is about ten times the size of the effect that would be expected based on a reduction in diarrheal deaths alone (Kremer et al. 2020).

\subsection{Study areas: mortality and exclusive breastfeeding}

The Kenyan under-5 mortality rate (2009-2014 period) is estimated at 44 deaths per 1,000 live births (DHS Kenya, 2014). The respective rates in Bungoma and Kakamega counties, our study areas, are estimated at 24 and 61 deaths per 1,000 live births (MICS Kenya, 2014). Of these deaths, 8 and 27 (per 1,000 live births) happen within the first month of life (neonatal period), and 10 and 21 (per 1,000 live births) happen between months 2 to 12 (post-neonatal period), in the

\footnotetext{
2 The Mills-Reincke phenomenon stems from independent observations by Hiram Mills and Julius Reincke that the introduction of water treatment in Lawrence, Massachusetts and Hamburg, Germany, respectively, were followed by reductions in deaths by typhoid fever, diarrheal and gastro-intestinal disease, but also by reductions in deaths from other causes - prominently deaths from "inflammatory disease of the respiratory organs" (Sedgwick and Macnutt, 1910).

${ }^{3}$ This mechanism is biologically plausible as diarrhea is a known risk factor for undernutrition which, in turn, is a risk factor for ALRI. Further, diarrhea can potentially increase the risk of ALRI through acute micronutrient loss, stress on the immune system, dehydration, and immobilization (Schmidt et al., 2009).
} 
respective county. Therefore, in both counties, about 3 in 4 deaths that occur within the first 5 years of life, happen in the first year.

In Bungoma and Kakamega, $32 \%$ and $20 \%$ of mothers, respectively, report giving their newborn liquids other than breast milk within their first 3 days of life: mainly plain water and sugar-salt solution (Table 1, Panel A, cols 1 and 2). ${ }^{4}$ Thus, exclusive breastfeeding in the first 3 days is $68 \%$ and $80 \%$, respectively. For children aged 0 to 2 months, it declines to 64 and 51 percent, and further declines to 33 and 20 percent for children aged 3 to 5 months, in the respective counties (Table 1, Panel B). The low exclusive breastfeeding rates early in life suggest that infants are likely exposed to contaminated water from a young age. These rates are somewhat lower than those in Kenya as a whole (Table 1, col 3).

\subsection{Background on dispensers}

Figure 1 provides images of a dispenser and illustrates how it works. The chlorine dispensers used in this project incorporate several insights from previous work and behavioral economics to achieve high levels of usage. First, they provide free chlorine, which has been shown to dramatically increase usage rates relative to paid provision (Kremer et al., 2009; Dupas et al., 2016). Second, they are installed immediately next to a communal water source such as a well or a naturally occurring spring or stream, making usage salient and public: The dispenser provides a daily visual reminder to households to treat their water at the moment when it is most salient - as water is collected. The public placement of dispensers at water sites also means that when people collect water, they can ask others about their experience using the dispenser, observe how to use it, and see whether others use it, potentially facilitating the development of social norms for dispenser use. Third, usage is also simple: The dispenser can be used by turning a knob, which triggers the release of a $3 \mathrm{ml}$ dose of dilute chlorine, sufficient to treat 20 liters of water (standard size of containers used to collect water). Thus, dispensers provide the correct dosage automatically, and transporting water from its source to the point of use (home) provides time and agitation for treatment, leading to reduced wait times at home until the water can be consumed. ${ }^{5}$ Fourth, the dispensers store dilute chlorine solution of the same type that is socially marketed through brands such as WaterGuard, increasing familiarity. Finally, dispensers provide chlorine free of charge. This feature reflects the finding that even small (non-monetary) costs dramatically reduce take-up (Dupas et al., 2016), while free provision does not measurably increase wastage from people using chlorine for other purposes, such as washing clothes or cleaning toilets (Ashraf et al., 2010). Local promoters are elected by the community to educate community members on how chlorine and the dispenser work, and why it is important to disinfect the water in order to raise chlorine usage. These promoters also help with the maintenance and refilling of the dispenser. The

\footnotetext{
${ }^{4}$ At the national level $15 \%$ of Kenyan mothers report feeding their newborns liquids other than breast milk (Table 1 , Panel A, col 3), and cite not having enough milk (51\%) and the baby crying too much (30\%) as the reasons for supplementation (Kenya DHS, 2014). We lack data, representative at the county level, on reasons for supplementation.

${ }^{5}$ WaterGuard instructions of usage suggest a $3 \mathrm{~mL}$ dose for each $20 \mathrm{~L}$ of water (the standard jerry-can size), or double this dose for highly turbid water. After mixing the solution, users should agitate the water recipient briefly, and let it sit for 30 minutes before consuming. The water might present a smell and strong chlorine taste immediately after treatment but this dissipates over time. The excess consumption of chlorine can lead to health problems such as cancer and reproductive issues. However, since the solution is sufficiently dilute, it does not pose serious health threats if ingested directly. (Source:

https://www.engineeringforchange.org/solutions/product/waterguard/ and Kremer et al. 2011)
} 
dispenser tank holds three liters of dilute chlorine solution, enough to treat a monthly supply for a community of 200 to 400 people.

Kremer et al. (2011) conducted a randomized controlled trial showing that take-up of chlorine provided through dispensers dramatically exceeded take-up of chlorine for treating water for in-home use provided through free coupons. When communities were randomly assigned to treatment with a promoter and a community dispenser, take-up was approximately $40 \%$ in the short run (three weeks), and then climbed and was sustained at approximately $50 \%$ from three months to two years into the program. In contrast, free monthly coupon distribution proved initially promising at $30 \%$ in the short run (3 weeks to 6 months), but resulted in much lower coupon redemption over time: Just $12.3 \%$ of households that were given coupons 12 months into the program redeemed them. Dupas et al. (2016) find similar results with coupons, with take-up at approximately $30 \% 3$ to 5 months after enrollment. The increase in water treatment usage rates under dispensers is also larger than that found using other approaches such as information provision or behavioral marketing (Madajewicz et al. 2007; Jalan and Somanathan 2008; Luoto 2014; Tarozzi et al. 2009).

\subsection{The WASH Benefits/Evidence Action intervention}

A flow diagram of the geographical units and sample of children considered in the WASHB study (Null et al., 2018) and in the present analysis is presented in Figure 2. The Kenya WASHB study (NCT01704105) evaluated the effect of water treatment, improved sanitation, handwashing, nutritional supplementation, and combinations of these interventions on early child development, in particular, on child diarrhea and growth. ${ }^{6,7}$ These interventions were assigned at the village level; here, we focus only on households in 65 villages which received water treatment interventions, and households in 67 control villages. We therefore exclude households in villages which received sanitation, handwashing, or nutrition interventions. There were two control groups: an active control group that received monthly visits to measure children's arm circumferences; and a passive control group that received no visits. We focus on the passive control group for the purposes of this study because it provides the policy-relevant treatment effect of delivering the intervention vs. no intervention, and because the "active control" villages were not surveyed by John \& Orkin, 2018. Because the passive control group is the focus of this study, we use the terms "control" and "passive control" interchangeably.

Villages in three Kenyan counties (Bungoma, Kakamega, and Vihiga) were eligible for participation if they were rural, the majority of inhabitants relied on communal water sources (e.g., springs, streams, boreholes, public taps) and had unimproved sanitation facilities, and if there were no other ongoing interventions related to water, sanitation, handwashing, or nutrition. A total of 1343 villages were excluded on the basis of these criteria. This implies that the eligible villages likely had higher diarrhea and diarrhea mortality rates than the county average. Within the 1,226 villages enrolled in the original study, WASH-B enrolled pregnant women in their second or third gestational trimester between November 2012 and May 2014. Neighboring villages with enrolled

\footnotetext{
${ }^{6}$ This sub-section draws heavily from Arnold et al. (2013) and Null et al. (2018).

${ }^{7}$ The improved sanitation intervention consisted of upgrading unimproved latrines by installing a plastic slab with a tight-fitting lid and constructing new latrines for households that did not own a latrine (or whose latrine was unlikely to last for 2 years). The handwashing intervention consisted of the installation of two handwashing stations per compound. The nutritional supplementation intervention promoted exclusive breastfeeding up to age 6 months, and provided children of ages 6 to 24 months with two sachets per day of a lipid-based nutrient supplement.
} 
women were grouped into "clusters" of up to three villages, to ensure that there were at least 6 enrolled women per cluster. A total of 8,246 women, grouped into 702 clusters, were enrolled in the original study. In this paper, we focus on 2,046 women in 132 villages of the original WASH study which received water treatment interventions.

In the original study, there were 9 distinct treatment and control arms, and blocked randomization was performed as follows. Clusters were grouped in "blocks" of 9 clusters each. Approximately 3 weeks after enrollment, the clusters were randomized into the treatment and control arms. The randomization was stratified by blocks, and the implementation of the interventions was stratified in 8 waves of approximately 10 adjacent blocks. ${ }^{8}$ Households in the active control and treatment arms were visited monthly by health promoters. Enrolled children, i.e., those born from the second and third trimester pregnancies identified at enrollment, were referred to health facilities if identified as possibly malnourished during routine visits. No such visits occurred in the passive control group.

In all water treatment clusters, sodium hypochlorite dispensers for point-of-collection water treatment were installed at all water sources used by enrolled women that met WASH-B Kenya eligibility criteria (an average of 5 water sites per cluster) and refilled as needed. The WASH-B Kenya eligibility criteria were that sources (i) were located in study villages, (ii) were used by more than one compound ${ }^{9}$, (iii) were not dry or turbid for more than four months a year, (iv) could be accessed free of charge, and (v) consent was obtained from the landowner to install the dispenser. The WASH-B promoters encouraged the use of these dispensers among community members. In addition, family compounds in dispenser villages, with children under five years of age, were given one-liter bottles of dilute chlorine solution for point-of-use water disinfection every six months, to last for approximately six months, for the first year of the intervention only. Further, the subset of these compounds with enrolled women continued to receive bottled chlorine, at the same rate, through the second year. Once opened, bottled dilute chlorine solution is recommended to be used within two months, as the introduction of air reduces its potency. It has a shelf life of one year if left unopened. ${ }^{10}$ Thus, any effects associated with the distribution of free bottled chlorine at the household level are expected to dissipate soon after the distribution stopped. Also, local promoters visited the study compounds at least monthly during the first year and every other month thereafter delivering behavior change messages that focused on the treatment of drinking water for all children living in the household. Details of the sanitation, handwashing, and nutrition interventions can be found in Null et al. (2018).

After the two years of the Kenya WASH-B study, the NGO Evidence Action continued resupplying (to date) dispensers in Bungoma and Kakamega counties. The present study focuses on the 349 dispensers installed in water treatment villages, of which Evidence Action continued operating 255 after the end of the original WASH-B study. Dispensers installed during the original WASH-B study located at water sources where Evidence Action's criteria ${ }^{11}$ were not satisfied

\footnotetext{
${ }^{8}$ Enrollment in the first wave happened between November and December 2012, while enrollment in subsequent waves started only in July 2013 and was completed over the following 10 months.

${ }^{9}$ A compound is a fenced unit where multiple households live together (Haushofer et al. 2018).

${ }^{10}$ See http://misaccess.psi.org/bcc_catalog/web/files/FO\%20Manual\%201.2final.pdf

11 The criteria included (i) the water source was not dry for at least 9 months, (ii) the flow rate was not too low (could fill a 1-liter container in under 12 seconds), (iii) the water source was not turbid, (iv) the water source was used for drinking, (v) at least 10 households used the source per year (calculated as the weighted average of users during the dry and wet season), and (vi) the attitude of the landowner was not "negative" towards dispensers, and they were not disliked by the community.
} 
were dropped from the program after the end of the original WASH-B study; this applies to 221 dispensers across the entire WASH-B study, and 70 in the water treatment villages that are the focus of this paper. In addition, Evidence Action installed 500 new dispensers (many of which replaced the 221 dispensers whose supply was not continued) across these same clusters; of these, 129 are in the water treatment villages on which we focus here. In our sample, $37 \%$ of households in treatment villages and $1.85 \%$ of households in control villages have a dispenser at their closest water point. It is important to note that the addition and removal of dispensers from the treatment villages by Evidence Action does not bias our treatment effects; it simply means that we study the combined effect of the initial roll-out and subsequent refinement of the program.

Like in the original WASH-B study, Evidence Action uses local promoters elected by the community to educate community members on how chlorine and the dispenser work, and why it is important to disinfect the water. These promoters also help with the maintenance and refilling of the dispenser.

\section{Data}

We use data from John \& Orkin (2018), a study of water treatment behavior conducted in the same area as the WASH-B study. Among the original 265 WASH-B villages, it focused on the 205 villages in Bungoma and Kakamega counties. Between October 2017 and January 2018, John \& Orkin (2018) recruited all 3,750 women in these villages who met the following criteria: aged 18-35 inclusive between October 2017 and January 2018, ii) within this age range, the most senior woman in their household, and iii) their household did not participate in the WASH Benefits study or they did not have children of an age that could have made them eligible for WASH-B enrollment (recall that WASH-B included only pregnant women in their second or third gestational trimester between November 2012 and May 2014). Note, however, that they did not exclude 384 women who did not have children at the beginning of the WASH-B study, but who gave birth during the first year of the study; these women received WaterGuard for the household up to the end of the first year of the study (see Figure 3 for a timeline across interventions). Women enrolled in the John \& Orkin (2018) study completed a baseline survey; received two psychological interventions aimed at increasing forward-looking behavior; and then completed an endline survey between February and March 2018. In addition, they received an unannounced household visit in AprilMay 2018 to measure chlorine levels in their drinking water.

In the present paper, among the 205 villages covered by John \& Orkin, we focus on the 132 villages (in 82 clusters of 1-3 villages) which had been assigned to the water treatment arm (65 villages) or the control arm (67 villages) during WASH-B. ${ }^{12}$ This results in a sample of 2,970 women in these 132 villages recruited by John \& Orkin. ${ }^{13}$

The data that we use to assess treatment effects on mortality, diarrhea, and other selfreported outcomes come from the endline survey conducted by John \& Orkin in February-March 2018 , to which 2,284 women of the originally recruited 2,970 responded (23\% attrition; not differential across treatment and control group, $23 \%$ vs. 23\%; p-val: 0.994). We further restrict this sample to women who had a live birth since January 2008 (i.e. approximately in the 10 years prior to the John \& Orkin survey), resulting in a sample of 2,013 mothers who gave birth to a total

\footnotetext{
12 Due to a coding error during randomization the sample by John \& Orkin (2020) also included some villages outside the WASH-B water treatment and control arms. We exclude these villages because we are interested in the comparison of the water treatment and control arms only.

${ }^{13}$ In the original WASH-B study, 131 villages were assigned to the water treatment arm, and 134 to the control arm, resulting in a total of 1,811 participating children.
} 
of 4,437 children after $2008 .{ }^{14}$ In our difference-in-difference analyses, we additionally exclude 428 children who were born in the year of the intervention rollout, because for them we cannot distinguish whether they were born in months before or after the rollout (we only know birth year, not month). Thus, we focus on those born in years before or after the year of the rollout, which consists of 4,009 out of the 4,437 children born after January 2008. In our ANCOVA analyses, we focus on the 1,981 out of the 4,437 children who were born after that date. However, for robustness, we also report analyses at the child-year level, which include all partially exposed children.

The self-reported data on chlorination in Table 3 comes from John \& Orkin's baseline survey, which covered 1,611 out of the 2,013 women in our sample. Of these, 1,352 responsed to the questions on self-reported chlorination (16\% non-response; not differential across treatment and control, $16.1 \%$ vs. $16.0 \%$; p-val: 0.949$)$.

The data that we use to assess treatment effects on objective measures of chlorination in Table 3 come from the surprise visit household conducted by John \& Orkin in April-May 2018 (11 weeks after the beginning of their study on average). To make the sample comparable to the self-report sample described above, we again exclude John \& Orkin's “pure control” group. Of the 1,611 households, we have objective chlorination data from 1,514 (6\% attrition; not significantly differential across treatment and control group, $7 \%$ vs. 5\%; p-val: 0.167 ).

The endline survey administered by John \& Orkin (2018) included questions on: (i) the number of pregnancies that resulted in a live birth since January 2008 and (ii) the number of children born after January 2008 who were alive at the time of the survey. When the former was larger than the latter, surveyors asked for confirmation on the number of child deaths (calculated as the difference of these two numbers). In addition, data were collected on the birth (and death) year of all live births born since January 2008. ${ }^{15}$ For children who died, John \& Orkin (2018) also collected data on the month of birth and death. These data allow us to examine mortality effects over a longer period of time (four to five years after the rollout of the intervention) and across a sample of children over twice as large as previously analyzed (Null et al., 2018), so the number of child-years involved is close to 3 times as large. ${ }^{16}$ The questionnaire relevant to this paper is shown in the appendix.

In addition, we use data on the presence of chlorine in household drinking water, collected during a surprise household visit between May-June 2018 (13 weeks after the beginning of the John \& Orkin study on average). Enumerators filled a vial with stored household drinking water

\footnotetext{
${ }^{14}$ Note that we cannot measure attrition in this subsample because John \& Orkin did not ask about live births since 2008 in their baseline.

${ }^{15}$ This procedure adequately captures the total number of live births and child deaths among mothers who did not give birth to twins from January 2008 until the time of the survey. For mothers who gave birth to twins and who lost exactly one child since January 2008, however, this procedure would miss that one death (as the number of pregnancies resulting in a live birth since January 2008 would match the number of live children born since January 2008 at the time of the survey). However, twinning is rare, with only $1.7 \%$ of the women enrolled in Kenya WASH Benefits giving birth to twins. Furthermore, this measurement error is likely unrelated to treatment status.

${ }^{16} 2,010$ children were born after dispensers were installed, on average 2.84 years old at the time of the survey (assuming no deaths). There are 2,064 children who were born between 2008 and the year before dispensers were installed, who would have been on average 2.47 years old by the end of this period (again assuming no deaths). The total number of child years covered in the data by John \& Orkin (2020) is estimated to be $(2,010 * 2.84)+(2,064 * 2.47)=10,806.48$. For comparison, Null et al. (2018), examined 3,622 child years, calculated as the number of enrolled children times the number of years they were followed.
} 
in the house and added DPD chlorine reagent powder, which discolors the water depending on how much chlorine it contains. Enumerators then compared the color of the water to a comparison chart to estimate whether and how much chlorine it contained, ranging from $0 \mathrm{mg} / \mathrm{l}$ to $3.4 \mathrm{mg} / \mathrm{l}$. This test was conducted separately for Total Chlorine Residual (TCR) and Free Chlorine Residual $(\mathrm{FCR})^{17}$; we use the latter because it indicates whether chlorine has been added to water and, if so, whether it contains enough chlorine to make it safe to drink. We create two versions of the Free Chlorine Residual variable: a continuous one, and an indicator variable for there being more than $0.1 \mathrm{mg} / \mathrm{l}$ of free chlorine residual in the water (i.e. presence of any amount of chlorine, allowing for some measurement error).

\section{Methodology}

This study estimates the intent-to-treat effect of the community-wide provision of dilute chlorine solution through dispensers and household delivery on all-cause child mortality. We estimate the following model for our sample of children born after the block-by-block rollout of the WASH-B Kenya intervention:

$$
Y_{i, c, w}=\beta_{0}+\beta_{1} T_{c, w}+\beta_{2} Y_{c, w}^{p r e}+\gamma_{w}+\varepsilon_{i, c, w}
$$

where $Y_{i, c, w}$ is an indicator variable for whether child $i$, in cluster $c$ and wave $w$, has died by age 5 (or 2), for children born after rollout of the treatment. $T_{c, w}$ is an indicator variable for living in a cluster randomized to community-wide provision of dilute chlorine solution (W), $\gamma_{w}$ are wave fixed effects, and $\varepsilon$ is an error term, possibly correlated within a cluster. Following McKenzie (2012), we condition on the pre-intervention under-5 (under-2) mortality rate of cluster $c, Y_{c, w}^{p r e}$, to improve statistical power (ANCOVA framework). The pre-intervention mortality rate is computed with all children born between January 1, 2008 and before the roll-out of the intervention. We will show that our results are robust to dropping this control. Standard errors are clustered at the cluster level, the unit of randomization. $\beta_{1}$ captures the risk-ratio intent-to-treat effect of the communitywide provision of dilute chlorine solution. We also present odds-ratio estimates using logistic regression.

We also estimate a difference-in-difference model which compares changes in mortality rates (before and after the intervention) across treatment and control areas for children born since January 1, 2008:

$$
Y_{i, c, w}=\beta_{0}+\beta_{1} T_{c, w}+\beta_{2} \text { Post }_{w}+\beta_{3} T_{c, w} \cdot \text { Post }_{w}+\gamma_{w}+\varepsilon_{i, c, w}
$$

where Post $_{i, c, w}$ is an indicator variable for years after the rollout of the WASH-B Kenya intervention, which varied at the block level. The roll out date is different for different waves. As before, we cluster standard errors at the 'cluster' level. $\beta_{3}$ is the difference-in-difference estimand of the effect of the community-wide provision of dilute chlorine. We also present odds-ratio estimates using logistic regression.

For robustness, we also report estimates from analogous analyses at the child-year level which includes both children fully exposed and children partially exposed to treatment.

\footnotetext{
${ }^{17}$ TCR tests for the presence of any amount of chlorine in the water while FCR tests whether there is still enough chlorine in the water to keep it sanitized. While FCR is more reliable to measure potability of water, TCR is capable of detecting whether any quantity of chlorine has been to the water at some point.
} 
For each model, we first estimate the effect of the community-wide provision of dilute chlorine solution through dispensers and WaterGuard on under-2 and under-5 mortality. ${ }^{18,19} \mathrm{We}$ will look at the impact of both bottled chlorination and dispensers together, as well as just dispensers by focusing on children born at least one year after the rollout of the intervention, who therefore would not have benefitted from the provision of WaterGuard. We also conduct a robustness check in which we exclude children born after the start of the psychological interventions studied by John \& Orkin (2018).

Second, we split up the previous results further in order to examine mortality effects at different times after birth among children who survived until a certain age. In particular, we examine effects on neonatal (< 1 month), post-neonatal ( $1 \leq$ months $<12)$ and child ( 1 $\leq$ years $<5$ ) mortality. We chose these periods following the analysis of the global burden of disease due to diarrhea (and other infectious diseases) by Gakidou et al. (2017). This strategy will identify the post-natal periods where observed mortality is reduced and shed insight on survival dynamics. For example, weak newborns who would have died during the neonatal period (absent water treatment) could potentially survive their first month because of the intervention, but die in the post-neonatal period. Such a situation would lead to reduced observed mortality rates in the neonatal period (relative to the control), but potentially higher mortality rates in the post-neonatal period - even if water treatment were to never increase the risk of death.

There is little in-migration aside from return migration in the study areas. However, though unlikely to account for the magnitude of our results, there is some concern that the intervention could have potentially incentivized health-conscious women to move out of, and/or into, villages where dispensers were not installed, leading to selection bias in our estimates. ${ }^{20} \mathrm{We}$ are partially able to address this concern by focusing on mothers who had multiple children, at least one before and one after the intervention: For these mothers, we can use mother fixed effects, i.e. examine changes in child mortality risk (before and after the intervention), among children of the same mother, across treatment and control areas. To account for the fact that mothers are older postintervention, we (flexibly) control for the age of the mother at the time of the child birth. ${ }^{21}$

In the appendix, we include results on the intent-to-treat effect of the community-wide provision of dilute chlorine solution on the risk of child diarrhea (Appendix Table A3).

\footnotetext{
${ }^{18}$ Because the children in our sample were born between January 2008 and April 2018 and the mortality data from John \& Orkin (2020) were collected between January and April 2018, the data on under one, two, and five mortality are censored for some children (depending on the mortality variable, date of birth of the child, and the WASH Benefits wave). We note that, in our context, censoring would likely bias our mortality estimates towards zero, as they do not take into account the (potential) deaths associated with waterborne infection that would occur over the censored period.

${ }^{19}$ We note that the estimates of the under- 5 and under- 2 mortality effects, based on the changes in mortality rates, are likely biased towards zero as some of the children in the pre-intervention period benefited from dispensers at some point in their first five or two years of life. This issue is less severe in the estimation of under-2 mortality, as the majority of children in the pre-intervention period were not able to benefit from dispensers in their first two years of life.

${ }^{20}$ This would be the case if maternal health-consciousness is associated with lower or higher child mortality risk.

${ }^{21} \mathrm{We}$ include indicator variables for ages within the following 3 year windows: $<12,12-14,15-17,18-20,21-23,24-$ 26, 27-29, 30-32, and 33-35.
} 


\section{Results \\ 5.1. Main results}

Four to five years after the start of WASH-B, maternal and household characteristics were not statistically different between treatment and control areas (Table 2). About $92 \%$ of mothers in our sample were married or cohabiting, 30\% had some secondary education (or higher), and $44 \%$ were employed, and differences between treatment and control are not statistically significant. Very few households had electricity (7\%), about $15 \%$ of households had improved floors (including tiles, cement, plaster, bricks, and/or stones), $90 \%$ owned their own house, $87 \%$ owned their plot of land, and $50 \%$ collected water from improved water sources (including public and private taps and public protected wells).

The original WASH-B study found that $40 \%$ of enrolled households in the treatment areas had detectable free chlorine in their stored drinking water one year after the intervention, dropping to $20 \%$ after two years. Prior to the intervention, at enrollment, only $3 \%$ of enrollment households had detectable free chlorine in their stored drinking water in both the treatment and control areas. ${ }^{22}$

We find that 4 years after the original WASH-B study, households from treatment areas are still more likely to have higher objective and self-reported measures of chlorine in their drinking water (see Table 3). Households in treatment areas have higher free chlorine residual scores (0.24) compared to the control group (0.15), and are more likely to have a free chlorine residual score above 0.1 (i.e. presence of any chlorine, accounting for potential testing error). Both differences are statistically significant at the 1 percent level. Mothers from treatment areas are also more likely to self-report usually chlorinating their water $(65 \%$ in the treatment compared to $50 \%$ in the control group), having chlorinated their water in the past 30 days (71 vs. 58\%), and obtaining chlorine from dispensers at the water source (31 vs. 11\%), though these measures may be subject to reporting bias. Again, all differences are statistically significant at the 1 percent level. Free chlorine residual presence and self-reported rates serve as lower and upper bounds of the true chlorination rate respectively. Null and Lantagne (2012) show that both self-reported treatment and chlorine residual presence are related to E. coli contamination reduction. They argue that the disparity between the two measures can partially be attributed to chlorine residual degradation during storage, which decreases only the objective measures. For this reason, even water samples that test negative for free chlorine residual might have been effectively treated against E. coli contamination. Additionally, Evidence Action reports an average program-wide adoption rate of $51 \%$ (as of July/August 2019) amongst those who use their eligible water sources. ${ }^{23}$ The original WASH-B study found that $39 \%$ of enrolled households in the treatment areas had detectable free chlorine in their stored water in the first year of the study, and $23 \%$ in the second year.

Using our preferred ANCOVA approach, we estimate that the provision of dilute chlorine solution reduced under-5 mortality by 1.41 p.p. (95\% CI: 0.27 p.p., 2.55 p.p.), or a $63 \%$ decrease

\footnotetext{
22 Null et al. (2018) did not test stored drinking water for chlorine among the passive control group postintervention. However, in the active control group, the share of households with detectable free chlorine in their stored drinking water remained at $3 \%$ one and two years after the intervention.

23 This adoption rate is calculated as follows: Evidence Action randomly selects $1.5 \%$ of water sources with dispensers for monitoring every 2 months, and obtains a list of households using the water source from the promoter. Chlorine is then measured in 8 randomly selected households amongst these households, and the adoption rate is defined as the share of households whose water contains detectable free chlorine. We emphasize that this selection process focuses on households using a water source with a dispenser, and therefore provides an upper bound for dispenser usage among all households in the village.
} 
from a base of $2.23 \%$ in the passive control group (Table 4, col 5). Further, we estimate that the intervention led to a reduction in under- 2 mortality risk of 1.36 p.p. (95\% CI: 0.18 p.p., 2.54 p.p.), or a $67 \%$ decrease from a base of $2.03 \%$ (column 2). The difference-in-differences estimate of the effect of dilute chlorine solution on under-5 mortality is a reduction of 1.46 p.p. (95\% CI: 0.12 p.p., 2.80 p.p.), or a $65 \%$ decrease (column 6). The difference-in-differences estimate of the effect of dilute chlorine solution on under- 2 mortality is a reduction of 1.47 p.p. (95\% CI: 0.05 p.p., 2.89 p.p.), or a $72 \%$ decrease (column 3). The estimates of the effect on mortality risk (columns 2 and 5) are similar when omitting baseline controls (columns 1 and 4), and when using logistic regression (Panel B). The odds ratio point estimate for our preferred ANCOVA approach is 0.27 (95\% CI: $0.09,0.45)$, which can be interpreted as a $73 \%$ reduction in mortality risk. ${ }^{24}$ We show that the results are robust to child-year level specifications that include children born after the roll out but with partial exposure to the intervention (see Appendix Table A1).

We next consider different subsamples by age. We cannot reject the hypothesis that the effects on neonatal (first month after birth), and child (years 2-5) mortality are equal to zero (see Table 5). The point estimate of the post-neonatal $(1 \leq$ months $<12)$ mortality effect is a reduction of 0.59 p.p. (95\% CI: -0.05 p.p., 1.22 p.p.),. or a $65 \%$ reduction. The odds-ratio estimate, 0.23 (95\% CI: $-0.11,0.56)$, is statistically significant at the 5 percent level, while the linear estimate is significant at the 10 percent level. Our child-year specification finds consistent results where we can only reject the effects of community-wide provision of dilute chlorine solution on mortality are significantly different from zero in the first year of life (see Appendix Table A1).

Recall that the study by John \& Orkin (2018) administered two psychological treatments. Their goal was to increase chlorination and decrease diarrhea. Their study also contained a placebo group in addition to a pure control group. Because the delay between their intervention and endline was very short (11 weeks on average), it is unlikely that these treatments affected mortality. However, they may have affected both self-reported and actual rates of chlorination. Because the psychological interventions were cross-randomized relative to the WASH-B randomization, they should not bias the estimated WASH-B treatment effects on these outcomes. Nevertheless, we conduct a robustness check in which we exclude the 55 children born after the John \& Orkin (2018) intervention to women who were part of one of their treatment groups, or their placebo group (see Appendix Table A4). The linear probability estimate is a 1.45 p.p. (95\% CI: 0.28 p.p., 2.62 p.p.) decrease for $<5$ mortality and a 1.40 p.p. (95\% CI: 0.19 p.p., 2.61 p.p.) decrease for $<2$ mortality, both significant at the 5 percent level. The results are similar when using logistic regression.

\subsection{Robustness checks}

The mortality effects that we estimate in this paper potentially arise due to a combination of (i) the availability of chlorine dispensers that have operated uninterruptedly since the beginning of the intervention, and (ii) the provision of bottled chlorine solution. Note that the John \& Orkin (2018) study excluded mothers who would have been eligible for the WASH-B study at the beginning of the study. However, they did not exclude the 384 women who gave birth during the first year of the WASH-B study and therefore became eligible at that point to receive WaterGuard

\footnotetext{
24 Odds ratio measures the relative odds of death under treatment versus control. For rare events, such as death, odds ratios and probability ratios are approximately equal.
} 
for the household up to the end of the first year of the study. As a first robustness check, we therefore re-estimate our main results excluding these children (see Table 6). We estimate that the mortality effects of the intervention are of similar magnitudes as before. The linear probability estimate is a 1.24 p.p. (95\% CI: 0.07 p.p., 2.41 p.p.) decrease for $<5$ mortality and a 1.31 p.p. $(95 \%$ CI: 0.07 p.p., 2.55 p.p.) decrease for $<2$ mortality, both significant at the 5 percent level. The results are similar when using logistic regression.

Second, because it is possible that the provision of WaterGuard during the first year of the WASH-B study also influenced these women's use of WaterGuard later on, we also conduct a robustness check in which we exclude these women from the sample entirely (including all of their children, rather than just those born shortly after the beginning of the intervention), see Table 7. Again, we estimate that the mortality effects of the intervention are of similar magnitudes as before. The linear probability estimate is a 1.61 p.p. (95\% CI: 0.26 p.p., 2.96 p.p.) decrease for $<5$ mortality and a 1.70 p.p. (95\% CI: 0.28 p.p., 3.12 p.p.) decrease for $<2$ mortality, both significant at the 5 percent level. The results are similar when using logistic regression.

To control for the possibility that some mothers may have moved as a result of treatment, we also include a specification which focuses on mothers who had at least one child before and one after the start of WASH-B (see Appendix Table A2). By doing this, we include only mothers that already lived in the same village before the intervention. To account for mother age differences, we include dummy variables for ages within the following 3 year windows: <12, 1214, 15-17, 18-20, 21-23, 24-26, 27-29, 30-32, and 33-35. Our main estimates for under 5 mortality remain negative and significantly different from zero at the 1 percent level (column 5). Our main odds ratio estimate for under- 2 mortality in column 2 is negative and significantly different from zero at the 1 percent level, while the linear estimate is negative but not significantly different from zero. For under-5 mortality, the main estimate of reduction in mortality risk is 1.55 p.p. (95\% CI: 0.11 p.p., 2.99 p.p.), significant at the 5 percent level. We note that this specification includes $45 \%$ fewer observations than the main specification, leading to reduced power to detect these effects. Together, these results suggest that our main findings are not driven by mothers moving in response to the treatment.

\subsection{Mechanisms}

A prominent possible mechanism for the effects of chlorine dispensers on mortality is a reduction in child diarrhea. To investigate this mechanism, we present results on the effects of the community-wide provision of dilute chlorine solution on child diarrhea in Appendix Table A3. In our preferred specification (column 1), the estimate is based on the number of diarrheal episodes in the past three months among children under 15 years of age (in early 2018), which was collected by John \& Orkin (2018) at endline during surveys with enumerators. This is the same data that John \& Orkin (2018) use for their analysis. We find that the estimated diarrhea risk is 4.35 p.p. lower in treatment villages (95\% CI: 0.51 p.p., 8.19 p.p.), significant at the 5 percent level. The odds ratio estimate from logistic regression, shown in column 3, shows a $25 \%$ reduction in the mortality odds, and is also significant at the 5 percent level. We do not find evidence for a reduction in diarrhea risk among children under 5 (columns 2 and 4). We note that these diarrhea estimates should be taken with a grain of salt for at least two reasons. First, they include diarrhea data from children older than 5 years, who might be affected to a lesser extent by water chlorination. Second, it involves a recall period of 3 months, which might be too long to capture differences in diarrhea incidence, especially among young children. John \& Orkin also asked questions about any diarrheal episode in the past two weeks among all children at baseline. We do not find significant 
results with this measure. We note that these are non-standard measures of diarrhea. In addition, they may be subject to social desirability bias.

Another possible mechanism for the effects on child mortality is that the arrival of dispensers also increased other health behaviors in treatment villages, e.g. because dispensers made the importance of such behaviors salient. To address this possibility, we use data from the endline survey of John \& Orkin to test the effect of treatment on self-reported health behaviors such as handwashing, washing fruits and vegetables before eating, and vaccinating children and taking them to health checkups. In Appendix Table A6, we find only 3 differences across 22 variables which are significant at the $10 \%$ level, which is roughly what we would expect by chance; when we use FDR correction for multiple inference, none of these differences is significant. Thus, dispensers seem to not have affected health behaviors other than water chlorination.

\subsection{Can the decrease in diarrhea explain the mortality effect?}

Our estimate of the effect of the community-wide provision of dilute chlorine solution on under-2 mortality, -1.36 p.p. (95\% CI: 0.18 p.p., 2.54 p.p.), based on an ANCOVA analysis comparing the intervention and passive control arms, is quantitatively similar to the (much less precise) estimate that is obtained using the data from Null et al. (2018) for enrolled children. ${ }^{25}$ When comparing the dispenser group to the passive control group, Null et al. (2018) find a mortality reduction of 1.10 p.p. $(95 \%$ CI $-0.69,2.89)$ through the provision of dilute chlorine solution, albeit not significantly different from zero. ${ }^{26}$ However, note that the households in Null et al.'s treatment group received promoter visits, which resulted in referrals to health clinics for malnourished children. In their passive control group, no such visits and referrals were made. Thus, the observed treatment effect could be partly driven by these referrals. Indeed, when comparing the treatment to the active control group, which receive no chlorine but did receive promoter visits and thus referrals, Null et al. found that the provision of dilute chlorine solution in addition to referrals reduced under- 2 mortality by only 0.30 p.p. (95\% CI $-1.20,1.90)$. Importantly, however, our sample includes only families who did not participate in the original WASH-B study and therefore did not receive referrals; thus, our treatment effects cannot be explained in this way.

Next, we ask to what extent the effect on mortality we observe can be explained by decreases in diarrhea. Our basic finding is that both our estimate of the mortality effect, and that obtained using the data from comparing the water treatment and passive control arms in Null et al. (2018), are larger in absolute value than the effect that would be expected if (i) reductions in child mortality caused by diarrhea were proportional to previously estimated reductions in diarrhea prevalence due to water chlorination, and (ii) non-diarrheal deaths were unaffected by water chlorination. To see this, we first assume that the effect of point-of-collection water chlorination on diarrhea prevalence is the same as the effect of point-of-use water chlorination. The effect of

\footnotetext{
${ }^{25}$ Null et al. (2018) were focused on child development, not child survival, though they collected and reported results on mortality while acknowledging that their design was not sufficiently powered. While the data of Null et al. (2018) do not lend themselves to difference-in-differences estimation, we note that our difference-in difference estimate of the under- 2 mortality effect is 0.35 p.p. (32\%) larger than the post-intervention estimate using the data by Null et al. (2018).

${ }^{26}$ We computed this estimate based on the raw mortality rates reported by Null et al. (2018) for these groups. Assuming an intra-cluster correlation (ICC) coefficient of zero, the p-value of the test of the hypothesis of a zero mortality effect is 0.230 .
} 
point-of-use water chlorination on diarrhea prevalence is estimated in the meta-analysis by Clasen at al. (2015) as 39\%. Given the under-2 mortality rate in the passive control group of $2.23 \%$, and assuming further that the mortality share due to diarrheal disease is $9.9 \%$ (Global Burden of Disease Study, 2017), we estimate a rate of under-2 mortality due to diarrhea of $0.22 \%$. Thus, we would expect a $0.22 * 0.39=0.09$ p.p. reduction in the risk of under- 2 child mortality due to diarrhea from the provision of dilute chlorine solution. Our estimates of the under- 2 mortality effect are thus almost fifteen times as large as the expected reduction, and their $95 \%$ confidence intervals (0.18 p.p., 2.54 p.p.) are sufficiently narrow such that we can reject the hypothesis that the effect is a reduction in under- 2 mortality of 0.09 p.p.

The underestimation of the actual reduction in child mortality based on diarrhea prevalence has several potential explanations. The first of them is measurement error. There may be a systematic bias and/or noise in caregiver-reported diarrhea. In fact, previous studies have found evidence suggesting that the way the questions are asked can influence the responses (Schmidt and Cairncross 2009, Zwane et al. 2010). Both social desirability bias and a lack of understanding about the identification of diarrhea can impact caregivers' answers.

Second, estimates from the Global Burden of Disease Study (GBD) of the diarrheal death rate are severely limited by data availability and require strong modelling assumptions to fill the gaps left by the data. As stated in GBD (2017), many datasets present biases or errors, including misclassifications of causes of death or the identification of causes that are not the primary. ${ }^{27}$ In addition, not all sources of uncertainty are included in the models, which makes it impossible to evaluate the precision of the estimates (see GBD 2017 for more details). ${ }^{28}$

Third, water treatment may have a larger effect on severe diarrhea than on overall diarrhea. If severe diarrhea is responsible for most deaths caused by diarrhea, only measuring the reduction in overall diarrhea prevalence would lead to an underestimation of the reduction in mortality associated with diarrheal diseases. Rotavirus immunization is one example of a preventive health treatment that has a greater impact on severe diarrhea (Madhi et al., 2010; Santosham, 2010). Future work should study the effects of water treatment by the type of diarrhea.

Fourth, it is particularly difficult to identify diarrhea for the youngest group - infants who still consume significant amounts of breast milk and for whom normal stooling patterns can look like diarrhea (WHO 2017). Many studies do not measure diarrhea in this age group, potentially because children of this age are often assumed to be exclusively breastfed, and hence not greatly affected by diarrhea. However, according to the WHO, only 1 in 3 infants under six months are exclusively breastfed (Victora 2016). Walker et al. (2013a) find that approximately 50\% of under five deaths from diarrhea happen in the first year of life. Water treatment could also prevent deaths from sepsis among infants by facilitating cleaner births and postnatal care practices (Blencowe et al., 2011). Poor water quality and exposure to a more pathogenic environment is associated with preterm birth and low birth weight (Padhi 2015). In this study, we can only find evidence that the effects of community-wide provision of dilute chlorine solution on child survival are significantly different from zero in the first year of life.

\footnotetext{
${ }^{27}$ Verbal autopsy (VA) data sources depend on how accurately underlying cause of death is assigned and this is complicated by multimorbidities. This requires correction for under-registration and error code redistribution, but systematic problems still remain (GDB 2017). Sources of VA data also vary substantially in terms of the training provided and the instrument used in collecting the data.

${ }^{28}$ Such as the uncertainty in covariates used for modeling and from the statistical models used for many of the error code redistribution algorithms.
} 
Another potential explanation comes from the well-known Mills-Reincke phenomenon. It states that the exposure to enteric pathogens in water and diarrheal diseases may increase the risk of other diseases. Therefore, water treatment would not only reduce the impact of diarrhea but also of non-diarrheal infectious diseases that could directly or indirectly lead to death. There are several epidemiological studies supporting this hypothesis. For example, evidence suggests that diarrheal episodes increased the incidence of acute lower respiratory infection (ALRI) among children in Ghana, Nepal, India, Pakistan and Israel (Schmidt et al., 2009; Coles et al., 2005; Walker et al., 2013b; Ashraf et al., 2013). Life-threatening conditions and pathogens that are not necessarily associated with diarrhea could also be prevented with water treatment, for example hepatitis A and E, parasitic, as well as enteroviruses and the Salmonella Typhi and Paratyphi.

The continued exposure to diarrheal pathogens can increase the risk of infection for other diseases by altering the gut microbiome (Rouhani 2020), while episodes of infection may impair gut function and lead to undernutrition, increasing the risk of mortality. Evidence suggests that diarrheal pathogens are present in approximately 60 percent of non-diarrheal stools in young children, most of them consisting of bacteria that could be killed by water chlorination (Kotloff et al. 2013). A dysbiotic or immature microbiome in childhood may negatively impact growth by failing to protect the intestinal barrier leading to villous blunting, mucus degradation, intestinal permeability, impaired immune responses, and susceptibility to malnutrition (Subramanian et al. 2014). The gut microbiome can also affect the response to oral vaccines (e.g. rotavirus, oral polio), recovery from diarrhea ${ }^{29}$, and the virulence of certain enteropathogens ${ }^{30}$. In addition, since the gut microbiome plays a protective role against pneumonia (Schuijt 2016), its modulation could help prevent this disease.

Diarrhea can also lead to malnutrition (Guerrant et al., 1992; Subramanian 2014 et al.), which in turn increases the risk of mortality from a range of illnesses, or simply from malnutrition itself. While there is significant evidence associating malnutrition to mortality, strong causal links to diarrhea have not yet been established. John \& Orkin (2018) did not record cause of death, but future studies should conduct verbal autopsies in order to understand the extent to which deaths from diarrheal versus non-diarrheal infectious diseases are averted.

In sum, there are several reasons why water treatment may have large effects on mortality despite diarrhea only being moderately affected. We therefore believe the impact of water treatment on mortality we report here reflects partly an effect on diarrhea, and partly an effect that operates through other mechanisms.

\section{Cost-effectiveness analysis}

In this section we examine the cost-effectiveness of community-wide provision of dilute chlorine solution through chlorine dispensers. ${ }^{31}$ We take the estimated cost of installing and maintaining chlorine dispensers at scale in western Kenya from the "Dispensers for Safe Water" (DSW) program operated by Evidence Action (2017), which is about USD 9.13 per child under five served, per year. ${ }^{32}$ We only include benefits of reduced child mortality risk, and thus ignore

\footnotetext{
${ }^{29}$ Recovery from diarrhea is mediated by the microbial community that may be disrupted by pathogens and "pathobionts" transmitted by water (e.g. in cholera, Hsiao 2014).

${ }^{30}$ For example, the pathogenic inflammatory effect of Giardia is amplified through coinfection with enteroaggregative E. coli which is associated with poor water quality (Bartlet 2017).

${ }^{31}$ We take a similar approach to cost-effectiveness analysis as Dupas et al. (2016).

32 This is calculated as the ratio of the total cost of the program (serving all community members) and the number of
} 
possible health gains through reduced child morbidity and health gains for people over the age of 5 years (see Table 8 ).

Based on our estimate of the effect of the community-wide provision of dilute chlorine solution on under-5 mortality (-1.41 p.p.), we estimate that the expected effect of water treatment on under-5 mortality, per year, in DSW areas in Kenya is -0.47 p.p., adjusting for usage rates. ${ }^{33}$ Thus, the cost of Evidence Action's operations is USD 1,941 per death of a child under 5 averted. Assuming that death within the first 5 years of life leads to the loss of 76 disability-adjusted life years (DALYs). ${ }^{34}$ Together, these calculations suggest that the provision of chlorine through Evidence Action's DSW program has a cost-effectiveness of USD 25 per DALY averted. ${ }^{35}$

This cost is far lower than the Kenyan GDP per capita (about USD 1,508 in 2017), which is the threshold suggested by the WHO to determine if interventions are "highly cost-effective" $(\mathrm{WHO}, 2014)^{36}$.

\section{Discussion}

We provide evidence that free provision of drinking water treatment solution through an approach designed to incorporate insights from behavioral economics can cost effectively improve child survival. Our study exploits the variation in dilute chlorine solution availability, induced by the Kenya WASH-B study (Null et al., 2018), and uses supplementary survey data recently collected from the WASH-B study areas (Haushofer et al., 2018). We find that the communitywide provision of dilute chlorine solution reduced all-cause under-5 mortality by 1.41 p.p. (95\% CI: 0.27 p.p., 2.55 p.p.) and all-cause under-2 mortality by 1.36 p.p. (95\% CI: 0.18 p.p., 2.54 p.p.), corresponding to decreases of 63 and $67 \%$, respectively. We also show that the intervention can be cost-effectively sustained at scale, with an estimated cost per DALY averted of about USD 25.

Our treatment effects are considerably larger than might have been expected based on multiplying the rates of chlorination, existing estimates of the impact of chlorination on diarrhea risk, and the diarrheal mortality rate. This suggests that the effects we report are explained by a general effect on health, rather than only an effect on diarrhea. In addition, our effect is much larger than those reported in previous studies; e.g., a recent meta-analysis estimates a mean reduction in mortality of $25.4 \%$ after providing dilute chlorine solution, about half the size of effects we find. Note, however, that our effect lies within its confidence interval, and we cannot reject that the two estimates are equal.

Another possible explanation for our large estimates is that there may have been disease outbreaks in our study area, leading us to observe a particularly big mortality effect during this time period, even if on average mortality effects are smaller. In line with this possibility, the treatment effect in one study district, Bumula, is $60 \%$ larger than in all other districts (Bungoma Central, Matungu, and Mumias). However, a test for the joint significance of these differences is

\footnotetext{
children under 5 served by dispensers.

33 This assumes that the average effect of the community-wide provision of dilute chlorine solution is proportional to take-up. Further, it assumes that this effect is entirely driven by dispensers, not the bottled chlorine distributed in the first year. Appendix Table A2 supports this assumption.

34 As recommended by the Disease Control Priorities Project.

${ }^{35}$ For comparison, the cost per DALY averted for Insecticide-Treated Nets and schistosomiasis deworming is between USD 5 to 31 (Jamison et al. 2006) and between USD 28 to 70 (Givewell 2012), respectively.

36 According to the WHO's criteria, interventions that can avert one DALY for less than the GDP per capita of a country are highly cost-effective; interventions that cost less than three times the GDP per capita level are still costeffective, while those that cost more than this threshold are not.
} 
not statistically significant $(\mathrm{F}(3,80)=1.67, p=0.18)$. Nevertheless, it is possible that the treatment may be particularly effective during disease outbreaks.

Finally, it is possible that chlorine dispensers may be particularly effective in reducing child mortality because they lead to more consistent levels of water treatment. Brown and Clasen (2012) show that correct, consistent and sustained use is necessary to realize the health gains from water quality interventions. The health benefits of improved quality drinking water are limited if even a small percentage of overall water consumed is of lower quality. A decline in adherence over time from $100 \%$ to $90 \%$ reduces predicted health gains by up to $96 \%$. Thus, future research might investigate whether dispensers lead to more consistent chlorination.

Our study has a few limitations. First, the new data collection effort did not include all the villages from the original WASH-B study, and did not cover the full population of women in each village. As a result, our estimates may be subject to sampling error, and our confidence intervals are large (95\% CI of the effect on all-cause under-5 mortality: 0.27 p.p., 2.55 p.p.). Second, our study was subject to substantial attrition; more than $20 \%$ of participants in the John \& Orkin (2018) study attrit between baseline and endline. Importantly, this attrition was balanced across treatment and control regions (John \& Orkin, 2018); however, it is possible that the non-attriting participants have larger treatment effects than others. Finally, our study is limited in that we do not have data on cause of death: Examining all-cause mortality, as opposed to mortality from infectious diseases, can introduce measurement error, and makes it harder to distinguish between possible mechanisms, e.g., what share of averted deaths was from diarrhea vs. other health consequences of contaminated water. Future work could address this issue by collecting verbal autopsies.

\section{References}

Alsan, M., Goldin, C. 2019. "Watersheds in Child Mortality: The Role of Effective Water and Sewerage Infrastructure, 1880 to 1920.” Journal of Political Economy, 127 (2), 586-638.

Arnold, B. F., and Colford, J. M. Jr. 2007. "Treating water with chlorine at point-of-use to improve water quality and reduce child diarrhea in developing countries: a systematic review and meta-analysis." The American Journal of Tropical Medicine and Hygiene 76.2, 354-364.

Arnold, B.F., Null, C., Luby, S.P., Unicomb, L., Stewart, C.P., Dewey, K.G., Ahmed, T., Ashraf, S., Christensen, G., Clasen, T., Dentz, H.N. 2013. "Cluster-randomised controlled trials of individual and combined water, sanitation, hygiene and nutritional interventions in rural Bangladesh and Kenya: the WASH Benefits study design and rationale." BMJ open, 3(8), p.e003476.

Ashraf, N., Berry, J., Shapiro., J. M. 2010. "Can Higher Prices Stimulate Product Use? Evidence from a Field Experiment in Zambia." American Economic Review, 100 (5), 2383-2413.

Ashraf, S., Huque, M. H., Kenah, E., Agboatwalla, M., Luby, S. P. 2013. "Effect of recent diarrhoeal episodes on risk of pneumonia in children under the age of 5 years in Karachi, Pakistan." International Journal of Epidemiology, Volume 42, Issue 1, pages 194-200, https://doi.org/10.1093/ije/dys233. 
Bhalotra, S. R., Diaz-Cayeros, A., Miller, G., Miranda, A., Venkataramani, A. S.. 2017. "Urban Water Disinfection and Mortality Decline in DevelopingCountries". No. w23239. National Bureau of Economic Research.

Black, R.E., Cousens, S., Johnson, H.L., Lawn, J.E., Rudan, I., Bassani, D.G., Jha, P., Campbell, H., Walker, C.F., Cibulskis, R., Eisele, T. 2010. "Global, regional, and national causes of child mortality in 2008: a systematic analysis." The lancet, 375(9730), pp.1969-1987.

Blencowe, H., Cousens, S., Mullany, L.C., Lee, A.C., Kerber, K., Wall, S., Darmstadt, G.L., Lawn, J.E. 2011. "Clean birth and postnatal care practices to reduce neonatal deaths from sepsis and tetanus: a systematic review and Delphi estimation of mortality effect". BMC Public Health, 11(3), p.S11.

Brandtzaeg, P. 2011. "The gut as communicator between environment and host: immunological consequences.” Eur J Pharmacol, 668(Suppl 1), S16-S32. doi:10.1016/j.ejphar.2011.07.006.

Brown, J., Clasen, T. 2012. "High Adherence Is Necessary to Realize Health Gains from Water Quality Interventions.” PLoS ONE, 7(5), e36735. https://doi.org/10.1371/journal.pone.0036735

Carles, G., Montoya, Y., Seve, B., Rakotofananina, T., Largeaud, M. and Mignot, V. 2002.

"Fièvre typhoïde et grossesse." Journal de gynécologie obstétrique et biologie de la reproduction, 31(5), pp.495-499.

Centers for Disease Control and Prevention. 2014a. "Chlorination.”Online: Centers for Disease Control and Prevention. https://www.cdc.gov/safewater/chlorination.html .

Centers for Disease Control and Prevention. 2014b. "Free Chlorine Testing." Online: Centers for Disease Control and Prevention. https://www.cdc.gov/safewater/chlorine-residual-testing.html .

Clasen, T. F., Alexander, K. T., Sinclair, D., Boisson, S., Peletz, R., Chang, H. H., Majorin, F., Cairncross, S.. 2015. "Interventions to improve water quality for preventing diarrhoea." Cochrane Database of Systematic Reviews, Issue 10. DOI:10.1002/14651858.CD004794.pub3. .

Coles, C.L., Fraser, D., Givon-Lavi, N., Greenberg, D., Gorodischer, R., Bar-Ziv, J., Dagan, R. 2005. "Nutritional status and diarrheal illness as independent risk factors for alveolar pneumonia." American journal of epidemiology, 162(10), pp.999-1007.

Crump, J. A., Otieno, P. O., Slutsker, L., Keswick, B. H., Rosen, D. H., Hoekstra, R. M., Vulule, J. M., Luby, S. P. 2005. "Household based treatment of drinking water with flocculantdisinfectant for preventing diarrhoea in areas with turbid source water in rural western Kenya: cluster randomised controlled trial." BMJ (Clinical research ed.), 331(7515), 478. doi:10.1136/bmj.38512.618681.E0

Cutler, D., Miller, G. 2005. "The role of public health improvements in health advances: the twentieth-century United States." Demography 42.1 , 1-22. 
Dadonaite, B., Ritchie, H. 2018. "Diarrheal diseases". Published online at OurWorldInData.org. Retrieved from: 'https://ourworldindata.org/diarrheal-diseases'

Dupas, P., Hoffmann, V., Kremer, M., Zwane, A.P. 2016. "Targeting health subsidies through a nonprice mechanism: A randomized controlled trial in Kenya." Science, 26;353(6302), 889-95. doi: 10.1126/science.aaf6288.

du Preez, M., Conroy, R. M., Ligondo, S., Hennessy, J., Elmore-Meegan, M., Soita, A., McGuigan, K. G.. 2011. "Randomized intervention study of solar disinfection of drinking water in the prevention of dysentery in Kenyan children aged under 5 years." Environmental science \& technology, 45.21, 9315-9323.

Evans, R. J. 1987. "Death in Hamburg: society and politics in the cholera years, 1830-1910". Oxford: Clarendon Press.

Evidence Action. 2017. "Dispensers for Safe Water: Innovation with Impact". Online: Evidence Action. https://www.evidenceaction.org/dispensers-2017/.

Evidence Action. 2019. "Dispensers for Safe Water: Cost-effectiveness Model Guide." Manuscript.

Gakidou, E., Afshin, A., Abajobir, A.A., Abate, K.H., Abbafati, C., Abbas, K.M., Abd-Allah, F., Abdulle, A.M., Abera, S.F., Aboyans, V. and Abu-Raddad, L.J., 2017. "Global, regional, and national comparative risk assessment of 84 behavioural, environmental and occupational, and metabolic risks or clusters of risks, 1990-2016: a systematic analysis for the Global Burden of Disease Study 2016.” The Lancet, 390(10100), pp.1345-1422.

Galiani, S., Gertler, P., Schargrodsky, E. 2005. "Water for life: The impact of the privatization of water services on child mortality." Journal of Political Economy 113.1, 83-120.

Gerber, A.S., Green, D.P. 2012. "Field experiments: Design, analysis, and interpretation." WW Norton.

Global Burden of Disease Collaborative Network. 2018. Global Burden of Disease Study 2017 (GBD 2017) Results. Seattle, United States: Institute for Health Metrics and Evaluation (IHME).

Guerrant, R.L., Schorling, J.B., McAuliffe, J.F., de Souza, M.A. 1992. "Diarrhea as a Cause and an Effect of Malnutrition: Diarrhea Prevents Catch-up Growth and Malnutrition Increases Diarrhea Frequency and Duration." The American Journal of Tropical Medicine and Hygiene, 47(1 Pt 2), 28-35.

John, A., and Orkin, K. 2018. "What motivates health behavior: Preferences, beliefs, or constraints? Evidence from psychological interventions in Kenya." Manuscript.

Jalan, J., E. Somanathan. 2008. "The importance of being informed: Experimental evidence on demand for environmental quality." Journal of Development Economics, 87(1), 14-28. 
Jamison, D. T. et al. 2006. “Disease control priorities in developing countries." 2nd ed. New York: Oxford University Press.

Kang, H. N., Park, H., Lee, H. J., Moon, J. H., Oh, J. Kim, C. R. 2018. "Rotavirus Infection as a Frequent Cause of Neonatal Fever." Pediatrics International, 60, 366-371. doi: $10.1111 /$ ped.13504

Kotloff, K.L., Nataro J.P., Blackwelder W.C., Nasrin, D., Farag, T. H., Panchalingam, S., Wu, Y., Sow, S. O., Sur, D., Breiman, R. F., Faruque, A. S., Zaidi, A. K., Saha, D., Alonso, P. L., Tamboura, B., Sanogo, D., Onwuchekwa, U., Manna, B., Ramamurthy, T., Kanungo, S., Ochieng, J. B., Omore, R., Oundo, J. O., Hossain, A., Das, S. K., Ahmed, S., Qureshi, S., Quadri, F., Adegbola, R. A., Antonio, M., Hossain, M. J., Akinsola, A., Mandomando, I., Nhampossa, T., Acácio, S., Biswas, K., O'Reilly, C. E., Mintz, E. D., Berkeley, L. Y., Muhsen, K., Sommerfelt, H., Robins-Browne, R.. M., Levine, M. M. 2013. "Burden and aetiology of diarrhoeal disease in infants and young children in developing countries (the Global Enteric Multicenter Study, GEMS): a prospective, case-control study." The Lancet, Volume 382, Issue 9888, 209 - 222.

Kremer, M., E. Miguel, S. Mullainathan, C. Null, A. Zwane. 2009. "Making Water Safe: Price, Persuasion, Peers, Promoters, or Product Design?” Working paper.

Kremer, M., Ahuja, A., Zwane, A. P. 2010. "Providing Safe Water: Evidence from Randomized Evaluations". Annual Review of Resource Economics 2:1, 237-256.

Kremer, M., Miguel, E., Mullainathan, S., Null, C. Zwane, A.P. 2011. "Social engineering: Evidence from a suite of take-up experiments in Kenya." Unpublished Manuscript, Harvard University, Cambridge, MA.

Kremer, M., Luby, S., Maertens, R., Tan, B. 2020. "Water Quality and Child Mortality: A MetaAnalysis." Manuscript.

Luoto, J., Levine, D., Albert, J., Luby, S. 2014. "Nudging to use: Achieving safe water behaviors in Kenya and Bangladesh." Journal of Development Economics, Volume 110, Pages 13-21.

Madajewicz, M., Pfaff, A., van Geen, A., Graziano, J., Hussein, I., Momotaj, H., Sylvi , R., Ahsan, H. 2007. "Can information alone change behavior? Response to arsenic contamination of groundwater in Bangladesh. "Journal of Development Economics, 84, (2), 731-754.

Madhi, S.A., Cunliffe, N.A., Steele, D., Witte, D., Kirsten, M., Louw, C., Ngwira, B., Victor, J.C., Gillard, P.H., Cheuvart, B.B., Han, H.H., Neuzil, K.M. 2010. "Effect of Human Rotavirus Vaccine on Severe Diarrhea in African Infants." New England Journal of Medicine, 362(4), pp. 289-298.

McKenzie, D. 2012. "Beyond baseline and follow-up: The case for more $\mathrm{T}$ in experiments. Journal of Development Economics, 99(2), pp.210-221. 
Newman, K. L., Gustafson, K., Englund, J.A., Magaret, A., Khatry, S., LeClerq, S. C., Tielsch, J. M., Katz, J., Chu, H. Y. "Effect of Diarrheal Illness During Pregnancy on Adverse Birth Outcomes in Nepal." Open Forum Infect Dis., 6(2), ofz011. doi: 10.1093/ofid/ofz011.

Null, C., Lantagne, D. 2012. "Microbiological quality of chlorinated water after storage in ceramic pots." Journal of Water, Sanitation and Hygiene for Development, 2 (4), 250-253.

Null, C., Stewart, C.P., Pickering, A.J., Dentz, H.N., Arnold, B.F., Arnold, C.D., BenjaminChung, J., Clasen, T., Dewey, K.G., Fernald, L.C.”, Hubbard, A.E. 2018. "Effects of water quality, sanitation, handwashing, and nutritional interventions on diarrhoea and child growth in rural Kenya: a cluster-randomised controlled trial." The Lancet Global Health, 6(3), pp.e316e329.

Nyambane, G., Ram, P.V., Regan, M., Null, C. 2018. "Implementation and Process Evaluation of a Large Scale Water, Sanitation, Hygiene and Nutrition Cluster-Randomized Controlled Trial in Western Kenya." Manuscript.

Padhi, B., Baker, K., Dutta, A., Cumming, O., Freeman, M., Satpathy, R., Das, B., Panigrahi, P. 2015. "Risk of adverse pregnancy outcomes among women practicing poor sanitation in rural India: a population-based prospective cohort study." PLoS Medicine, 12(7), e1001851. doi:10.1371/journal.pmed.1001851.

Panigrahi, P., Parida, S., Nanda, N. C., Satpathy, R., Pradhan, L., Chandel, D. S., Baccaglini, L., Mohapatra, A., Mohapatra, S. S., Misra, P. R., Chaudhry, R., Chen, H. H., Johnson, J. A., Morris, J. G., Paneth, N., Gewolb, I. H. 2017. "A randomized synbiotic trial to prevent sepsis among infants in rural India." Nature, 548(7668), 407-412. doi:10.1038/nature23480.

Rouhani, S., Griffin, N. W., Yori, P. P., Gehrig, J. L., Olortegui, M. P., Salas, M. S., Trigoso, D. R., Moulton, L. H., Houpt, E. R., Barratt, M. J., Kosek, M. N., Gordon, J. I. 2020. "Diarrhea as a Potential Cause and Consequence of Reduced Gut Microbial Diversity Among Undernourished Children in Peru." Clinical Infectious Diseases, 71(4), 989-999.

Santosham, M. 2010. "Rotavirus Vaccine - A powerful tool to combat deaths from diarrhea." New England Journal of Medicine, 362(4), pp. 358-360.

Schmidt, W. P., Cairncross, S. 2009. "Household water treatment in poor populations: is there enough evidence for scaling up now?" Environmental science \& technology 43.4, 986-992.

Schmidt, W.P., Cairncross, S., Barreto, M.L., Clasen, T., Genser, B., 2009. "Recent diarrhoeal illness and risk of lower respiratory infections in children under the age of 5 years." International journal of epidemiology, 38(3), pp.766-772.

Schuijt, T. J., Lankelma, J. M., Scicluna, B. P., de Sousa e Melo, F., Roelofs, J. J., de Boer, J. D., Hoogendijk, A. J., de Beer, R., de Vos, A., Belzer, C., de Vos, W. M., van der, P. T., Wiersinga, W. J. 2016. "The gut microbiota plays a protective role in the host defence against pneumococcal pneumonia.” Gut, 65(4), 575-83. doi:10.1136/gutjnl-2015-309728 
Sedgwick, W. T., MacNutt, J. S. 1910."On the Mills-Reincke Phenomenon and Hazen's Theorem Concerning the Decrease in Mortality from Diseases Other than Typhoid Fever Following the Purification of Public Water-Supplies." Journal of Infectious Diseases, 7.4, 489564.

Subramanian, S., Huq, S., Yatsunenko, T., Haque, R., Mahfuz, M., Alam, M. A., Benezra, A., DeStefano, J., Meier, M. F., Muegge, B. D., Barratt, M. J., VanArendonk, L. G., Zhang, Q., Province, M. A., Petri, W. A. Jr., Ahmed, T., Gordon, J. I. 2014. "Persistent gut microbiota immaturity in malnourished Bangladeshi children." Nature, 510(7505), 417-21. doi:10.1038/nature13421.

Tarozzi, A., Mahajan, A., Blackburn, B., Kopf, D., Krishnan, L., Yoong, J. 2009. “Commitment Mechanisms and Compliance with Health-protecting Behavior: Preliminary Evidence from Orissa (India)". American Economic Review: Papers and Proceedings, 99(2), 231-235.

The Demographic and Health Surveys (DHS) Program. 2014. "Kenya: Standard DHS, 2014". https://dhsprogram.com/what-we-do/survey/survey-display-451.cfm The MAL-ED Network Investigators. 2014. "The MAL-ED Study: A Multinational and Multidisciplinary Approach to Understand the Relationship Between Enteric Pathogens, Malnutrition, Gut Physiology, Physical Growth, Cognitive Development, and Immune Responses in Infants and Children Up to 2 Years of Age in Resource-Poor Environments." Clinical Infectious Diseases, Volume 59, Issue suppl_4, Pages S193-S206. https://doi.org/10.1093/cid/ciu653

Unicef Multiple Indicator Cluster Surveys (MICS). 2014. "Surveys - Kenya 2014". http://mics.unicef.org/surveys

Victora, C. G., Bahl, R., Barros, A. J., França, G. V., Horton, S., Krasevec, J., Murch, S., Sankar, M. J., Walker, N., Rollins, N. C., Lancet Breastfeeding Series Group. 2016. "Breastfeeding in the 21st century: epidemiology, mechanisms, and lifelong effect." Lancet, 387(10017), 475-90. doi:10.1016/S0140-6736(15)01024-7.

Walker, C.L.F., Rudan, I., Liu, L., Nair, H., Theodoratou, E., Bhutta, Z.A., O'Brien, K.L., Campbell, H., Black, R.E. 2013a. "Global burden of childhood pneumonia and diarrhoea." The Lancet, 381(9875), pp.1405-1416.

Walker, C.L.F., Perin, J., Katz, J., Tielsch, J.M., Black, R.E., 2013b. "Diarrhea as a risk factor for acute lower respiratory tract infections among young children in low income settings." Journal of global health, 3(1), 010402.

Wolf, J., Hunter, P.R., Freeman, M.C., Cumming, O., Clasen, T., Bartram, J., Higgins, J.P.T., Johnston, R., Medlicott, K., Boisson, S., Prüss-Ustün, A. 2018. "Impact of drinking water, sanitation and hand washing with soap on childhood diarrhoeal disease: updated meta-analysis and -regression." Trop. Med. Int. Health, 23(5), 508-525. 
World Health Organization. 2014. "Choosing interventions that are cost-effective." Geneva:

World Health Organization. http://www.who.int/choice/en/

World Health Organization. 2017. "Diarrhoeal Disease." Online: World Health Organization, Fact Sheet No 330. http://www.who.int/mediacentre/factsheets/fs330/en/.

World Health Organization. 2019. "Drinking-water." Online: World Health Organization. https://www.who.int/news-room/fact-sheets/detail/drinking-water. 
Figures

Figure 1: The Chlorine Dispenser

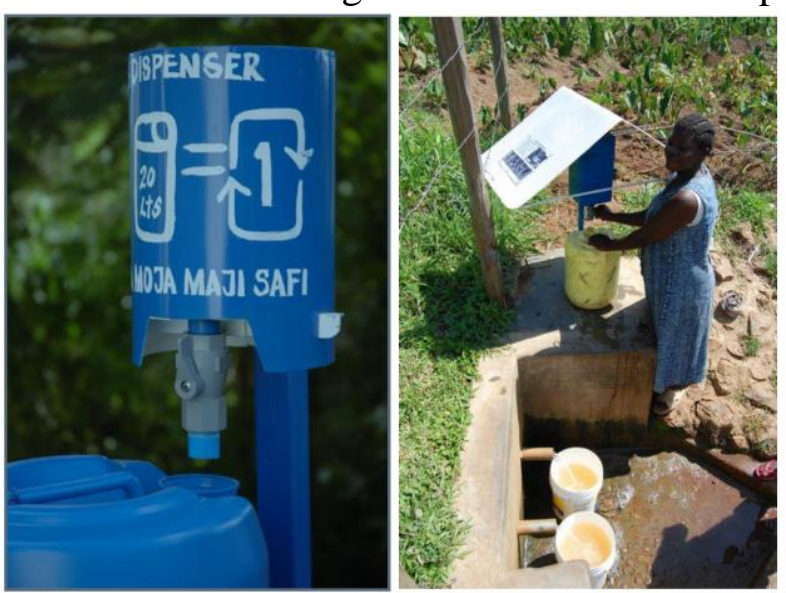

Source: Kremer et al. (2011)

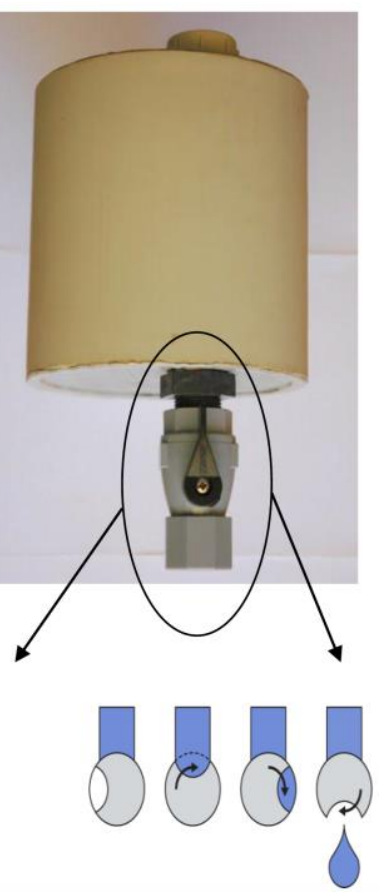


Figure 2: Flow diagram

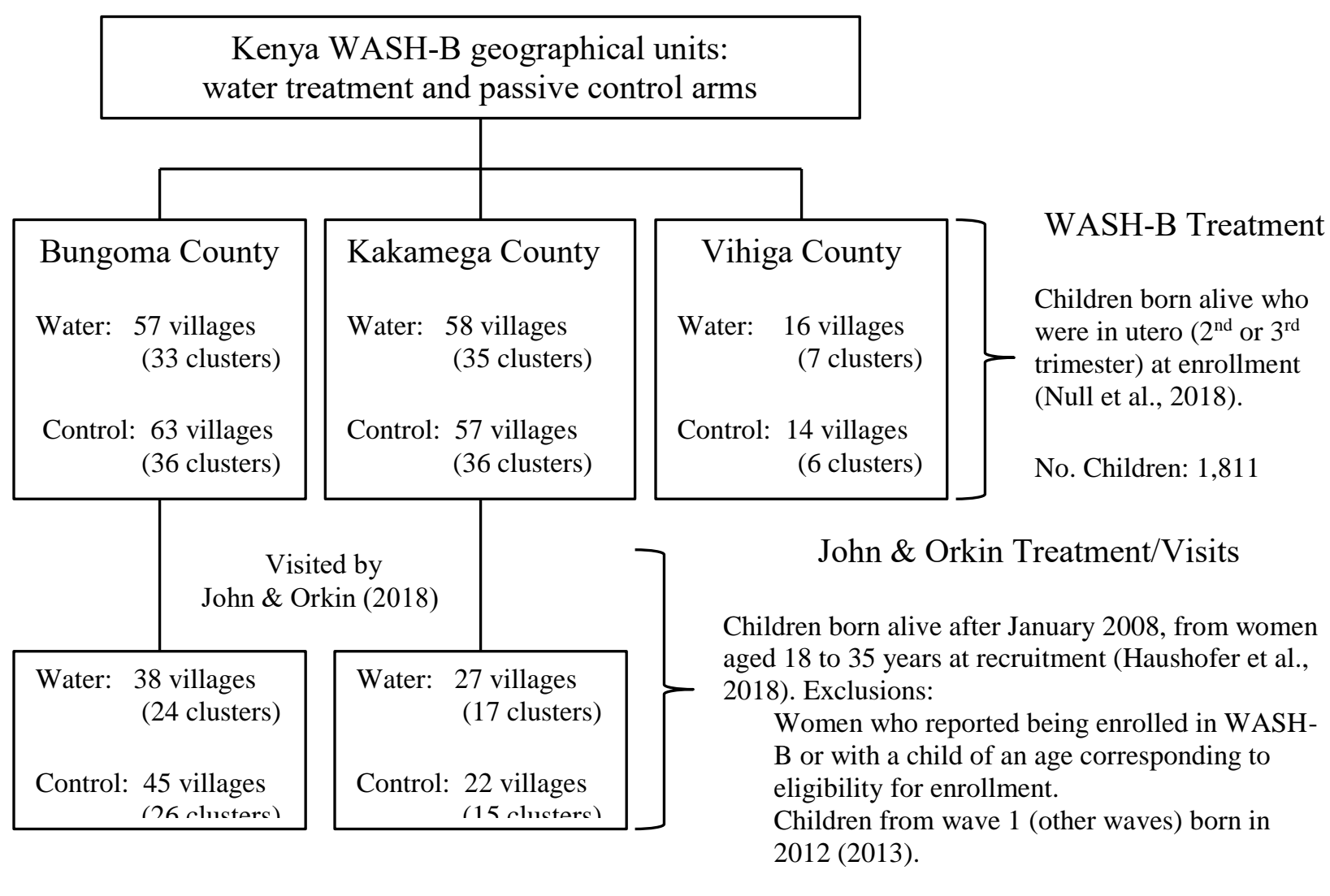

Number of Children: 4,437

Notes: The first wave of the Kenya WASH-B study enrolled children between November and December 2012, while enrollment in subsequent waves started only in July 2013 and was completed over the following 10 months. John \& Orkin (2018) recruited participants between October 2017 and January 2018.

Sources: John \& Orkin (2018), Null et al. (2018), and author's calculations 
Figure 3: Timeline for John \& Orkin (2018) treatment group

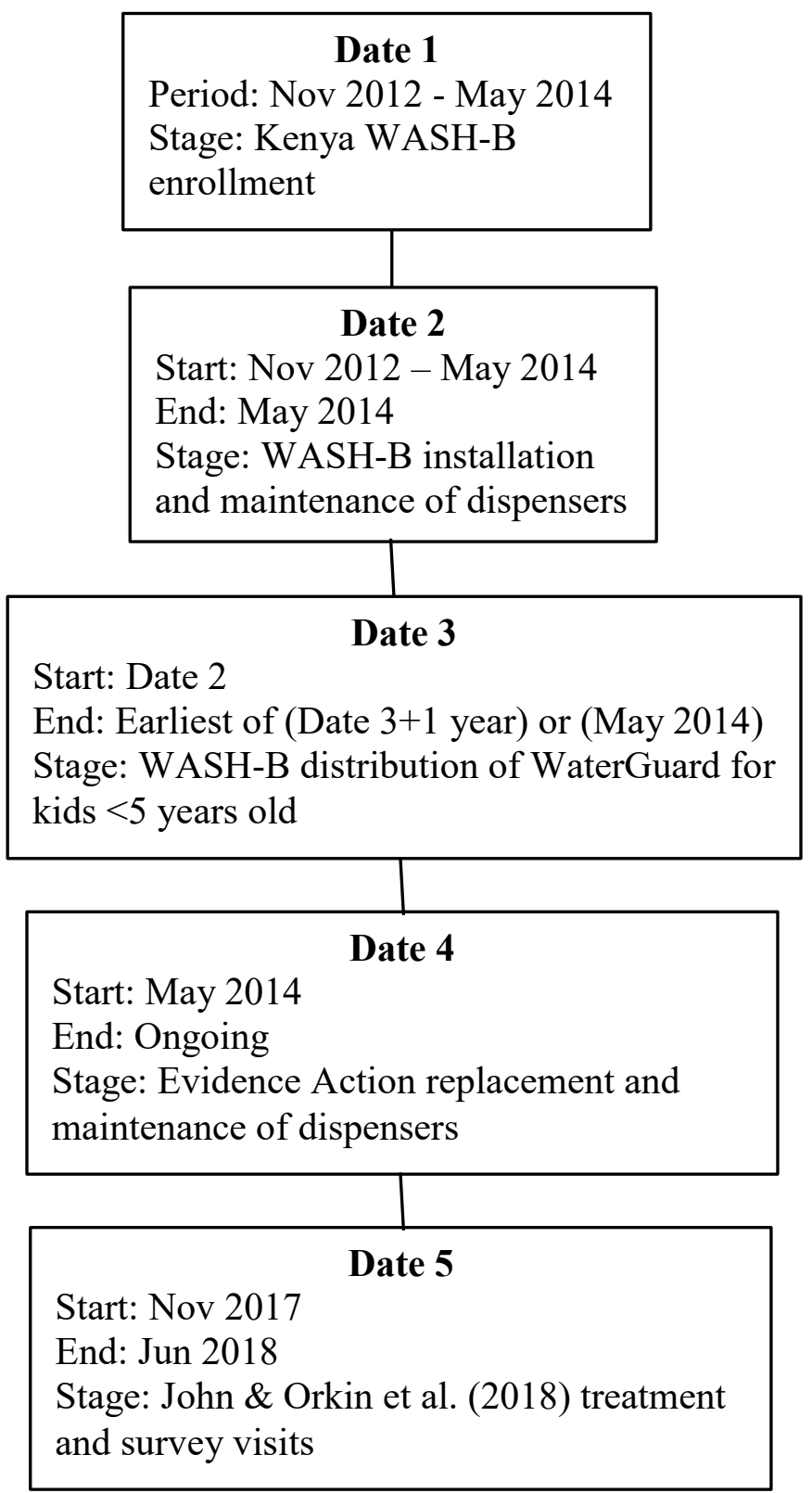

Notes: Date 1 does not present an end date since it was not an ongoing intervention in the villages. Different villages were enrolled to the program at different moments in time but the enrollment process of a village did not extend itself in time.

Sources: John \& Orkin (2018), Null et al. (2018), and author's calculations 


\section{Tables}

Table 1: Exclusive breastfeeding and mixed feeding in Kenya

\begin{tabular}{|c|c|c|c|}
\hline & $\begin{array}{c}\text { Bungoma } \\
1\end{array}$ & $\begin{array}{c}\text { Kakamega } \\
2\end{array}$ & $\begin{array}{c}\text { Kenya } \\
3\end{array}$ \\
\hline \multicolumn{4}{|c|}{ Panel A: Breastfeeding and mixed feeding rates in first 3 days of life } \\
\hline Excl. breastfeeding & 0.68 & 0.80 & 0.85 \\
\hline \multicolumn{4}{|l|}{ Other liquids } \\
\hline Pain water & 0.18 & 0.11 & 0.06 \\
\hline Sugar water & 0.01 & 0.01 & 0.04 \\
\hline Sugar-salt solution & 0.10 & 0.05 & 0.03 \\
\hline Other milk & 0.02 & 0.01 & 0.02 \\
\hline Formula & 0.00 & 0.00 & 0.01 \\
\hline Other liquid & 0.04 & 0.02 & 0.02 \\
\hline \multicolumn{4}{|c|}{ Panel B: Exclusive breastfeeding rates by child age (in months) } \\
\hline $0-2$ & 0.64 & 0.51 & 0.79 \\
\hline $3-5$ & 0.33 & 0.20 & 0.48 \\
\hline $6-8$ & 0.08 & 0.03 & 0.07 \\
\hline $9-11$ & 0.00 & 0.00 & 0.01 \\
\hline
\end{tabular}

Notes: Columns 1 and 2 show the mean rates in Bungoma and Kakamega counties, respectively, and column 3 shows the mean rates at the national level.

Source: Authors' calculations. Data representative at the county level for Bungoma and Kakamega counties (cols 1 and 2) come from Kenya MICS (2014) and data representative at the national level (col 3) come from Kenya DHS (2014). 
Table 2: Treatment vs. control balance

\begin{tabular}{lccccc}
\hline & $\begin{array}{c}\text { Mean } \\
\text { (Contro } \\
1)\end{array}$ & $\begin{array}{c}\text { Mean } \\
\text { (Treatme } \\
\text { nt) }\end{array}$ & $\begin{array}{c}\text { Diff. } \\
\text { estimate }\end{array}$ & Diff. s.e. & Obs. \\
& 1 & 2 & 3 & 4 & 5 \\
\hline Panel A: Maternal characteristics & & & & & \\
Married or cohabiting & 0.914 & 0.919 & -0.007 & 0.017 & 1611 \\
Secondary education or higher & 0.293 & 0.307 & 0.011 & 0.028 & 1611 \\
Employed & 0.430 & 0.462 & 0.044 & 0.066 & 1433 \\
Panel B: Household characteristics & & & & & \\
Has electricity & 0.072 & 0.056 & -0.013 & 0.024 & 1611 \\
Has improved floors & 0.153 & 0.148 & 0.000 & 0.023 & 1346 \\
Owns house & 0.898 & 0.898 & -0.007 & 0.015 & 1352 \\
Owns land & 0.862 & 0.877 & 0.010 & 0.021 & 1352 \\
HH uses improved water source & 0.527 & 0.488 & -0.034 & 0.035 & 1611 \\
High asset value & 0.516 & 0.515 & -0.001 & 0.040 & 1611 \\
\hline
\end{tabular}

Notes: Columns 1 and 2 show the means in the passive control and water treatment groups, respectively. Column 3 shows the point estimate of the difference in means between these arms. Women who were randomly assigned to the "pure control" arm in the experiment by John \& Orkin (2018) were not interviewed at baseline and are thus excluded from this analysis, explaining the smaller number of observations relative to the overall sample. Different numbers of observations across variables stem from missing data in John \& Orkin (2018). High asset value denotes participants who scored above the median in a measure of the value of their holdings of a limited list of common household assets. Estimation method is OLS. All regressions include wave fixed effects. Standard errors are clustered at the 'cluster' level and are presented in column 4. Significance: $* \mathrm{p}<0.1, * * \mathrm{p}<0.05$, *** $\mathrm{p}<0.01$.

Source: Authors' calculations, data by John \& Orkin (2018). 
Table 3: The effect of dilute chlorine solution provision on water treatment

\begin{tabular}{lccccc}
\hline & $\begin{array}{c}\text { Mean } \\
\text { (Contr } \\
\text { ol) }\end{array}$ & $\begin{array}{c}\text { Mean } \\
\text { (Treat } \\
\text { ment) }\end{array}$ & $\begin{array}{c}\text { Diff. } \\
\text { estimate }\end{array}$ & $\begin{array}{c}\text { Diff. } \\
\text { s.e. }\end{array}$ & Obs. \\
& 1 & 2 & 3 & 4 & 5 \\
\hline Free Chlorine Residual Score $(0-3.4)$ & 0.152 & 0.242 & $0.092^{* * *}$ & 0.042 & 1514 \\
Free Chlorine Residual Score $>0.1$ & 0.158 & 0.230 & $0.081^{* * *}$ & 0.036 & 1514 \\
HH usually chlorinates water & 0.499 & 0.648 & $0.153^{* * *}$ & 0.030 & 1352 \\
HH chlorinated water (past 30 days) & 0.577 & 0.706 & $0.131^{* * *}$ & 0.031 & 1352 \\
HH uses chlorine dispensers & 0.112 & 0.313 & $0.203^{* * *}$ & 0.033 & 1352 \\
\hline
\end{tabular}

Notes: Columns 1 and 2 show the means in the passive control and water treatment groups, respectively. Column 3 shows the point estimate of the difference in means between these arms. Data on free chlorine come from the surprise visit conducted by John \& Orkin at the end of their study. Self-reported data on chlorination come from John \& Orkin's baseline. The lower number of observations in the self-reported data results from the fact that John \& Orkin's "pure control" group were not surveyed at their baseline. Estimation method is OLS. All regressions include wave fixed effects. Standard errors are clustered at the 'cluster' level and are presented in column 4. Significance: ${ }^{*} \mathrm{p}<0.1,{ }^{* *}$ $\mathrm{p}<0.05, * * * \mathrm{p}<0.01$.

Source: Authors' calculations, data by John \& Orkin (2018). 
Table 4: The effect of dilute chlorine solution provision on all-cause mortality

\begin{tabular}{|c|c|c|c|c|c|c|}
\hline & (1) & (2) & (3) & (4) & (5) & (6) \\
\hline & $<2 \mathrm{y}$ & $<2 \mathrm{y}$ & $<2 \mathrm{y}$ & $<5 y$ & $<5 \mathrm{y}$ & $<5 y$ \\
\hline \multicolumn{7}{|c|}{ Panel A: Linear Probability Model } \\
\hline Treatment & $\begin{array}{l}-0.0119^{*} \\
(0.00596)\end{array}$ & $\begin{array}{l}-0.0136^{* *} \\
(0.00603)\end{array}$ & $\begin{array}{c}0.00154 \\
(0.00598)\end{array}$ & $\begin{array}{l}-0.0143^{* *} \\
(0.00593)\end{array}$ & $\begin{array}{l}-0.0141^{* *} \\
(0.00582)\end{array}$ & $\begin{array}{r}-0.000836 \\
(0.00605)\end{array}$ \\
\hline \multirow{2}{*}{$\begin{array}{l}\text { Treatment x Post- } \\
\text { Intervention }\end{array}$} & & & $-0.0147^{* *}$ & & & $-0.0146^{* *}$ \\
\hline & & & $(0.00722)$ & & & $(0.00684)$ \\
\hline Post-Intervention & & & $\begin{array}{c}0.00889 \\
(0.00717)\end{array}$ & & & $\begin{array}{c}0.00792 \\
(0.00673)\end{array}$ \\
\hline \multicolumn{7}{|c|}{ Panel B: Odds Ratio Estimates } \\
\hline Treatment & $\begin{array}{l}0.371^{*} \\
(0.191)\end{array}$ & $\begin{array}{l}0.170^{* * * *} \\
(0.0843)\end{array}$ & $\begin{array}{l}1.141 \\
(0.558)\end{array}$ & $\begin{array}{l}0.323^{* *} \\
(0.161)\end{array}$ & $\begin{array}{l}0.270^{* * *} \\
(0.0917)\end{array}$ & $\begin{array}{l}0.945 \\
(0.406)\end{array}$ \\
\hline \multirow{2}{*}{$\begin{array}{l}\text { Treatment x Post- } \\
\text { Intervention }\end{array}$} & & & $0.301^{* *}$ & & & $0.323^{* * * *}$ \\
\hline & & & $(0.147)$ & & & $(0.135)$ \\
\hline Post-Intervention & & & $\begin{array}{l}1.807 \\
(0.842)\end{array}$ & & & $\begin{array}{c}1.572 \\
(0.578)\end{array}$ \\
\hline Observations & 1981 & 1981 & 4009 & 1981 & 1981 & 4009 \\
\hline Wave FE & Yes & Yes & Yes & Yes & Yes & Yes \\
\hline $\begin{array}{l}\text { Pre-intervention } \\
\text { Mortality Control }\end{array}$ & No & Yes & No & No & Yes & No \\
\hline $\begin{array}{l}\text { Mean Dep. var. } \\
\text { (control - post } \\
\text { intervention) }\end{array}$ & .0203 & .0203 & .0203 & .0223 & .0223 & .0223 \\
\hline
\end{tabular}

Notes: The unit of observation is the child. The outcome variable is an indicator equal to 1 for children who died under the age of 2 (columns 1-3) or under the age of 5 (columns 4-6). The estimation method is OLS in Panel A and logistic regression in Panel B. Note that coefficients below 1 represent a negative treatment effect in logistic regressions. Standard errors are clustered at the 'cluster' level. Treatment is an indicator variable that is equal to 1 for children from clusters where chlorine dispensers were installed and 0 otherwise. Post is an indicator variable defined as 1 for children born after the installation of chlorine dispensers and 0 for children born before. Wave fixed effects are included in all columns. We condition on the cluster pre-intervention mortality rate in columns 3 and 6 . The sample is restricted to children born after the rollout of the intervention in columns 1,2, 4, and 5. All children are included in columns 3 and 6. Standard errors in parentheses ${ }^{*} p<0.1,{ }^{* *} p<0.05,{ }^{* * *} p<0.01$.

Source: Authors' calculations, data by John \& Orkin (2018). 
Table 5: The effect of dilute chlorine solution provision on all-cause mortality - by period

\begin{tabular}{lccc}
\hline & $\begin{array}{c}(1) \\
\text { Neonatal } \\
\text { mortality } \\
\text { (month 1) }\end{array}$ & $\begin{array}{c}(2) \\
\text { Post-neonatal } \\
\text { mortality } \\
\text { (months 2-12) }\end{array}$ & $\begin{array}{c}\text { Child mortality } \\
\text { (years 2-5) }\end{array}$ \\
\hline Panel A: Linear Probability Model & & & \\
Treatment & -0.00550 & $-0.00587^{*}$ & -0.00289 \\
& $(0.00367)$ & $(0.00325)$ & $(0.00185)$ \\
\hline Panel B: Odds Ratio Estimates & & & \\
Treatment & 0.372 & $0.226^{* * *}$ & 0.328 \\
& $(0.317)$ & $(0.170)$ & $(0.346)$ \\
\hline Observations & 1981 & 1969 & Yes \\
Wave FE & Yes & Yes & Yes \\
Pre-intervention Mortality & Yes & Yes & .0041 \\
Control & & & .0091 \\
Mean Dep. var. (control-post) & .0091 & & \\
\hline
\end{tabular}

Notes: The unit of observation is the child. The estimation method is OLS in Panel A and logistic regression in Panel B. Note that coefficients below 1 represent a negative treatment effect in logistic regressions. Standard errors are clustered at the 'cluster' level. All regressions include wave fixed effects. Treatment is an indicator variable that is equal to 1 for children from clusters where chlorine dispensers were installed and 0 otherwise. We condition on the cluster pre-intervention mortality rate. The sample is restricted to children born after the rollout of the intervention. The number of observations is smaller in columns 2 and 3 than in column 1 due to the omission of children who died before reaching that age range. Standard errors in parentheses ${ }^{*} p<0.1,{ }^{* * *} p<0.05,{ }^{* * *} p<0.01$.

Source: Authors' calculations, data by John \& Orkin (2018). 
Table 6: The effect of dilute chlorine solution provision on all-cause mortality - excluding children born within one year of the WASH-B rollout

\begin{tabular}{|c|c|c|c|c|c|c|}
\hline & $\begin{array}{l}(1) \\
<2 \mathrm{y}\end{array}$ & $\begin{array}{l}(2) \\
<2 \mathrm{y}\end{array}$ & (3) & $\begin{array}{l}(4) \\
<5 \mathrm{y}\end{array}$ & $\begin{array}{l}(5) \\
<5 \mathrm{y}\end{array}$ & $\begin{array}{l}(6) \\
<5 \mathrm{y}\end{array}$ \\
\hline \multicolumn{7}{|c|}{ Panel A: Linear Probability Model } \\
\hline Treatment & $\begin{array}{l}-0.0111^{*} \\
(0.00612)\end{array}$ & $\begin{array}{l}-0.0131^{* *} \\
(0.00630)\end{array}$ & $\begin{array}{c}0.00139 \\
(0.00574)\end{array}$ & $\begin{array}{l}-0.0128^{* *} \\
(0.00606)\end{array}$ & $\begin{array}{l}-0.0124^{* *} \\
(0.00596)\end{array}$ & $\begin{array}{r}-0.000972 \\
(0.00583)\end{array}$ \\
\hline \multirow{2}{*}{$\begin{array}{l}\text { Treatment x Post- } \\
\text { Intervention }\end{array}$} & & & $-0.0135^{*}$ & & & $-0.0127^{*}$ \\
\hline & & & $(0.00702)$ & & & $(0.00643)$ \\
\hline Post-Intervention & & & $\begin{array}{c}0.00625 \\
(0.00687) \\
\end{array}$ & & & $\begin{array}{c}0.00452 \\
(0.00621) \\
\end{array}$ \\
\hline \multicolumn{7}{|c|}{ Panel B: Odds Ratio Estimates } \\
\hline Treatment & $\begin{array}{l}0.353^{* *} \\
(0.186)\end{array}$ & $\begin{array}{l}0.146^{* * *} \\
(0.0765)\end{array}$ & $\begin{array}{c}1.125 \\
(0.531)\end{array}$ & $\begin{array}{l}0.317^{* *} \\
(0.160)\end{array}$ & $\begin{array}{l}0.320^{* * *} \\
(0.124)\end{array}$ & $\begin{array}{c}0.933 \\
(0.387)\end{array}$ \\
\hline \multirow{2}{*}{$\begin{array}{l}\text { Treatment x Post- } \\
\text { Intervention }\end{array}$} & & & $0.292^{* *}$ & & & $0.322^{* * *}$ \\
\hline & & & $(0.140)$ & & & $(0.127)$ \\
\hline Post-Intervention & & & $\begin{array}{c}1.562 \\
(0.746)\end{array}$ & & & $\begin{array}{c}1.324 \\
(0.491) \\
\end{array}$ \\
\hline Observations & 1597 & 1597 & 3625 & 1597 & 1597 & 3625 \\
\hline Wave FE & Yes & Yes & Yes & Yes & Yes & Yes \\
\hline $\begin{array}{l}\text { Pre-intervention } \\
\text { Mortality Control }\end{array}$ & No & Yes & No & No & Yes & No \\
\hline $\begin{array}{l}\text { Mean Dep. var. } \\
\text { (control - post) }\end{array}$ & .0177 & .0177 & .0177 & .0189 & .0189 & .0189 \\
\hline
\end{tabular}

Notes: The unit of observation is the child. The estimation method is OLS in Panel A and logistic regression in Panel B. Note that coefficients below 1 represent a negative treatment effect in logistic regressions. Standard errors are clustered at the 'cluster' level. The sample excludes children born in 2013 (in areas that were part of wave 1 of intervention rollout) or 2014 (in areas that were part of waves 2-7 of intervention rollout). Wave fixed effects are included in all columns. Treatment is an indicator variable that is equal to 1 for children from clusters where chlorine dispensers were installed and 0 otherwise. Post is an indicator variable defined as 1 for the years following the installation of chlorine dispensers and 0 for the years before. We condition on the cluster pre-intervention mortality rate in columns 3 and 6 . The sample is restricted to children born after the rollout of the intervention in columns 1,2 , 4, and 5. All children are included in columns 3 and 6. Standard errors in parentheses ${ }^{*} p<0.1,{ }^{* *} p<0.05,{ }^{* * *} p<$ 0.01 .

Source: Authors' calculations, data by John \& Orkin (2018). 
Table 7: The effect of dilute chlorine solution provision on all-cause mortality - excluding all children of mothers with any children born within one year of WASH-B

\begin{tabular}{|c|c|c|c|c|c|c|}
\hline & $\begin{array}{l}(1) \\
<2 \mathrm{y}\end{array}$ & $\begin{array}{l}(2) \\
<2 \mathrm{y}\end{array}$ & $\begin{array}{l}(3) \\
<2 \mathrm{y}\end{array}$ & $\begin{array}{l}(4) \\
<5 y\end{array}$ & $\begin{array}{l}(5) \\
<5 \mathrm{y}\end{array}$ & $\begin{array}{l}(6) \\
<5 \mathrm{y}\end{array}$ \\
\hline \multicolumn{7}{|c|}{ Panel A: Linear Probability Model } \\
\hline Treatment & $\begin{array}{l}-0.0147^{* *} \\
(0.00707)\end{array}$ & $\begin{array}{l}-0.0170^{* *} \\
(0.00724)\end{array}$ & $\begin{array}{l}-0.00118 \\
(0.00613)\end{array}$ & $\begin{array}{l}-0.0167^{* *} \\
(0.00700)\end{array}$ & $\begin{array}{l}-0.0161^{* *} \\
(0.00686)\end{array}$ & $\begin{array}{l}-0.00433 \\
(0.00583)\end{array}$ \\
\hline \multirow{2}{*}{$\begin{array}{l}\text { Treatment x Post- } \\
\text { Intervention }\end{array}$} & & & $-0.0144^{*}$ & & & $-0.0132^{*}$ \\
\hline & & & $(0.00781)$ & & & $(0.00708)$ \\
\hline Post-Intervention & & & $\begin{array}{c}0.00813 \\
(0.00781)\end{array}$ & & & $\begin{array}{r}0.00573 \\
(0.00701)\end{array}$ \\
\hline \multicolumn{7}{|c|}{ Panel B: Odds Ratio Estimates } \\
\hline Treatment & $\begin{array}{l}0.268^{* *} \\
(0.155)\end{array}$ & $\begin{array}{l}0.128^{* * *} \\
(0.0684)\end{array}$ & $\begin{array}{c}0.907 \\
(0.531)\end{array}$ & $\begin{array}{l}0.240^{* *} \\
(0.134)\end{array}$ & $\begin{array}{l}0.268^{* * *} \\
(0.124)\end{array}$ & $\begin{array}{c}0.732 \\
(0.334)\end{array}$ \\
\hline \multirow{2}{*}{$\begin{array}{l}\text { Treatment x Post- } \\
\text { Intervention }\end{array}$} & & & $0.278^{* *}$ & & & $0.313^{* * *}$ \\
\hline & & & $(0.143)$ & & & $(0.132)$ \\
\hline Post-Intervention & & & $\begin{array}{r}1.680 \\
(0.845) \\
\end{array}$ & & & $\begin{array}{c}1.361 \\
(0.514) \\
\end{array}$ \\
\hline Observations & 1405 & 1405 & 3049 & 1405 & 1405 & 3049 \\
\hline Wave FE & Yes & Yes & Yes & Yes & Yes & Yes \\
\hline $\begin{array}{l}\text { Pre-intervention } \\
\text { Mortality Control }\end{array}$ & No & Yes & No & No & Yes & No \\
\hline $\begin{array}{l}\text { Mean Dep. var. } \\
\text { (control - post) }\end{array}$ & 0204 & .0204 & .0204 & .0218 & .0218 & .0218 \\
\hline
\end{tabular}

Notes: The unit of observation is the child. The estimation method is OLS in Panel A and logistic regression in Panel B. Note that coefficients below 1 represent a negative treatment effect in logistic regressions. Standard errors are clustered at the 'cluster' level. The sample excludes all children of mothers with any children born within one year of WASH-B; i.e., all children of mothers with any live births in 2013 (in areas that were part of wave 1 of intervention rollout) or 2014 (in areas that were part of waves 2-7 of intervention rollout). Wave fixed effects are included in all columns. Treatment is an indicator variable that is equal to 1 for children from clusters where chlorine dispensers were installed and 0 otherwise. Post is an indicator variable defined as 1 for the years following the installation of chlorine dispensers and 0 for the years before. We condition on the cluster pre-intervention mortality rate in columns 3 and 6. The sample is restricted to children born after the rollout of the intervention in columns 1,2, 4, and 5. All children are included in columns 3 and 6. Standard errors in parentheses ${ }^{*} p<0.1,{ }^{* *} p<0.05,{ }^{* * *} p<0.01$.

Source: Authors' calculations, data by John \& Orkin (2018). 
Table 8: Cost-effectiveness analysis of the community-wide provision of dilute chlorine solution

\begin{tabular}{|c|c|c|}
\hline & & Source \\
\hline $\begin{array}{l}\text { 1. Intent-to-treat estimate of the provision of } \\
\text { water treatment on }<5 y \text { mortality (in p.p.) }\end{array}$ & -1.41 & Estimates are based on this study. \\
\hline $\begin{array}{l}\text { 2. Intent-to-treat estimate of the provision of } \\
\text { water treatment on }<5 \text { y mortality, per year (in } \\
\text { p.p.) }\end{array}$ & -0.38 & $\begin{array}{l}\text { Calculated as (1)/3.7, where } 3.7 \text { is the average } \\
\text { duration (in years) of the water treatment } \\
\text { intervention up to the survey by John \& Orkin } \\
(2018)\end{array}$ \\
\hline 3. Average take-up in WASH-B areas & 0.35 & $\begin{array}{l}\text { Calculated as the average of the self-reported } \\
\text { dispenser usage rate (Haushofer et al., 2018) and } \\
\text { the share of positive free chlorine residual tests } \\
\text { (Null et al., 2018) }\end{array}$ \\
\hline $\begin{array}{l}\text { 4. Average take-up rate in villages in Kenya } \\
\text { where Evidence Action (EA) operates its } \\
\text { Dispensers for Safe Water (DSW) program }\end{array}$ & 0.43 & $\begin{array}{l}\text { Evidence Action (2018), the average is taken over } \\
\text { the } 2016-2017 \text { period }\end{array}$ \\
\hline $\begin{array}{l}\text { 5. Expected effect of water treatment on }<5 y \\
\text { mortality, per year, in DSW areas in Kenya (in } \\
\text { p.p.) }\end{array}$ & -0.47 & Calculated as $(2)^{*}(4) /(3)$ \\
\hline $\begin{array}{l}\text { 6. Average cost of DSW in Kenya, per child } \\
<5 \text { y served, per year (in USD) }\end{array}$ & 9.13 & $\begin{array}{l}\text { Evidence Action (2017), the average is taken over } \\
\text { the } 2016-2017 \text { period }\end{array}$ \\
\hline $\begin{array}{l}\text { 7. Cost of DSW in Kenya, per death of a child } \\
<5 y \text { averted (USD) }\end{array}$ & 1941 & Calculated as $-(6) /((5) / 100)$ \\
\hline 8. Cost of DSW in Kenya, per DALY averted & 25.46 & $\begin{array}{l}\text { Calculated as (7)/ DALYs lost from child death } \\
<5 y\end{array}$ \\
\hline $\begin{array}{l}\text { 9. Cost per outcome as good as: averting the } \\
\text { death of an individual under } 5 \text { from } \\
\text { GiveDirectly (USD) }\end{array}$ & 11273 & GiveWell (2018) \\
\hline $\begin{array}{l}\text { 10. Cost per outcome as good as: averting the } \\
\text { death of an individual under } 5 \text { from } \\
\text { GiveDirectly, relative to DSW in Kenya }\end{array}$ & 5.8 & Calculated as $(9) /(7)$ \\
\hline
\end{tabular}

Notes: The estimate of the under-5 mortality effect from this study refers that in Table 3 Panel A column 5. The number of DALYs lost from death under 5 assumes a life expectancy of 81.25 years, and that deaths under 5 happen at age 5 .

Source: Authors' calculations, data by Evidence Action (2017, 2018), John \& Orkin (2018), and Null et al. (2018). 


\section{Appendix}

Table A1: The effect of dilute chlorine solution provision on all-cause mortality - child-year level specification

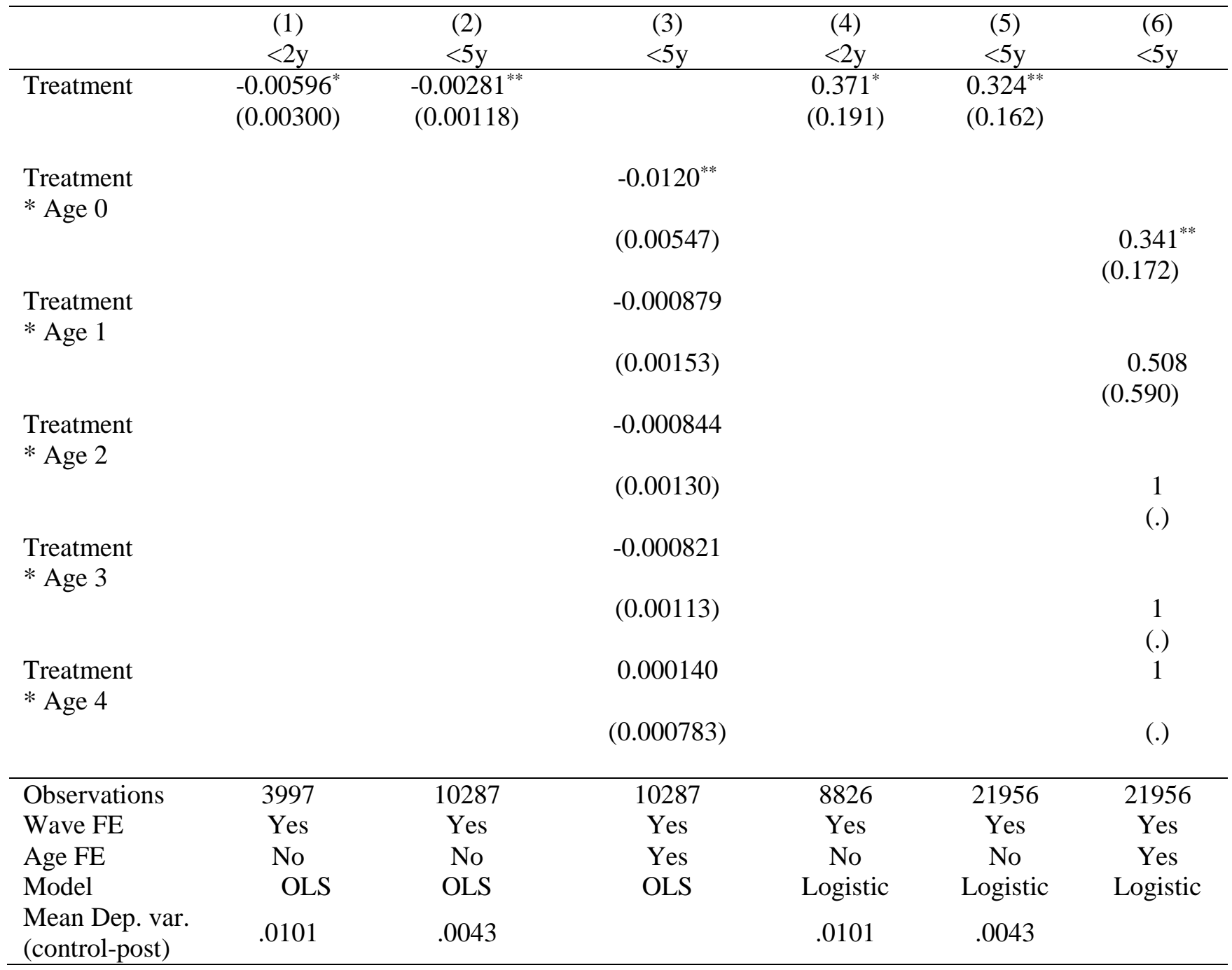

Notes: The unit of observation is a child-year: each living child appears in the data as many times as they are years old (starting with age 0 ) at the time of the survey, and the outcome is an indicator for them being still alive in the year in question. Each child who died appears in the data as many times as they were years old when they died (starting with age 0 ), and the outcome is an indicator for whether or not they died in the particular year in question. The sample is restricted to children born after the rollout of the intervention. The estimation method is OLS in columns 1-3, and logistic regression in columns 4-6. Standard errors are clustered at the 'cluster' level. Wave fixed effects are included in all columns. Age fixed effects are included in columns 3 and 6 . Treatment is an indicator variable that is equal to 1 for children from clusters where chlorine dispensers were installed and 0 otherwise. Standard errors in parentheses * $p<0.1,{ }^{* *} p<0.05,{ }^{* * *} p<0.01$.

Source: Authors' calculations, data by John \& Orkin (2018). 
Table A2: The effect of dilute chlorine solution provision on all-cause mortality - including only children of mothers who had a child before and after the intervention

\begin{tabular}{|c|c|c|c|c|c|c|}
\hline & $\begin{array}{l}(1) \\
<2 \mathrm{y}\end{array}$ & $\begin{array}{l}(2) \\
<2 \mathrm{y}\end{array}$ & (3) & $\begin{array}{l}(4) \\
<5 \mathrm{y}\end{array}$ & $\begin{array}{l}(5) \\
<5 \mathrm{y}\end{array}$ & $\begin{array}{l}(6) \\
<5 \mathrm{y}\end{array}$ \\
\hline \multicolumn{7}{|c|}{ Panel A: Linear Probability Model } \\
\hline Treatment & $\begin{array}{l}-0.00768 \\
(0.00795)\end{array}$ & $\begin{array}{c}-0.0115 \\
(0.00775)\end{array}$ & $\begin{array}{c}0.00458 \\
(0.00727)\end{array}$ & $\begin{array}{c}-0.0122 \\
(0.00810)\end{array}$ & $\begin{array}{l}-0.0155^{* *} \\
(0.00734)\end{array}$ & $\begin{array}{c}0.00298 \\
(0.00725)\end{array}$ \\
\hline \multirow{2}{*}{$\begin{array}{l}\text { Treatment x Post- } \\
\text { Intervention }\end{array}$} & & & -0.0144 & & & $-0.0165^{*}$ \\
\hline & & & $(0.00942)$ & & & $(0.00881)$ \\
\hline Post-Intervention & & & $\begin{array}{c}0.00669 \\
(0.00900)\end{array}$ & & & $\begin{array}{r}0.00765 \\
(0.00862)\end{array}$ \\
\hline \multicolumn{7}{|c|}{ Panel B: Odds Ratio Estimates } \\
\hline Treatment & $\begin{array}{c}0.590 \\
(0.380)\end{array}$ & $\begin{array}{l}0.176^{* * *} \\
(0.110)\end{array}$ & $\begin{array}{c}1.547 \\
(0.802)\end{array}$ & $\begin{array}{c}0.462 \\
(0.276)\end{array}$ & $\begin{array}{c}0.338^{* * *} \\
(0.139)\end{array}$ & $\begin{array}{l}1.309 \\
(0.597)\end{array}$ \\
\hline \multirow{2}{*}{$\begin{array}{l}\text { Treatment x Post- } \\
\text { Intervention }\end{array}$} & & & $0.327^{*}$ & & & $0.324^{* *}$ \\
\hline & & & $(0.206)$ & & & $(0.167)$ \\
\hline Post-Intervention & & & $\begin{array}{r}1.557 \\
(0.986) \\
\end{array}$ & & & $\begin{array}{c}1.506 \\
(0.780) \\
\end{array}$ \\
\hline Observations & 1117 & 1117 & 2515 & 1117 & 1117 & 2515 \\
\hline Wave FE & Yes & Yes & Yes & Yes & Yes & Yes \\
\hline $\begin{array}{l}\text { Pre-intervention } \\
\text { Mortality Control }\end{array}$ & No & Yes & No & No & Yes & No \\
\hline $\begin{array}{l}\text { Mean Dep. var. } \\
\text { (control - post) }\end{array}$ & .0200 & 0200 & 0200 & 0237 & 0237 & 0237 \\
\hline
\end{tabular}

Notes: The unit of observation is the child. The estimation method is OLS in Panel A and logistic regression in Panel B. Note that coefficients below 1 represent a negative treatment effect in logistic regressions. Standard errors are clustered at the 'cluster' level. The sample is restricted to children of mothers who had at least one child before and after the start of WASH-B. Wave fixed effects are included in all columns. Treatment is an indicator variable that is equal to 1 for children from clusters where chlorine dispensers were installed and 0 otherwise. Post is an indicator variable defined as 1 for the years following the installation of chlorine dispensers and 0 for the years before. We condition on the cluster pre-intervention mortality rate in columns 3 and 6 . We include dummies for ages within the following 3 year windows: <12, 12-14, 15-17, 18-20, 21-23, 24-26, 27-29, 30-32, and 33-35 in all columns. The sample is restricted to children born after the rollout of the intervention in columns 1, 2, 4, and 5. All children are included in columns 3 and 6. Standard errors in parentheses ${ }^{*} p<0.1,{ }^{* *} p<0.05,{ }^{* * *} p<0.01$.

Source: Authors' calculations, data by John \& Orkin (2018). 
Table A3: The effect of dilute chlorine solution provision on diarrhea

\begin{tabular}{|c|c|c|c|c|}
\hline & $\begin{array}{c}\text { (3) } \\
\text { Had diarrhea } \\
\text { in the past } 3 \\
\text { months }\end{array}$ & $\begin{array}{c}\text { (4) } \\
\text { Had diarrhea } \\
\text { in the past } \\
2 \text { weeks }\end{array}$ & $\begin{array}{c}\text { (1) } \\
\text { Had diarrhea } \\
\text { in the past } 3 \\
\text { months }\end{array}$ & $\begin{array}{c}\text { (2) } \\
\text { Had diarrhea } \\
\text { in the past } 2 \\
\text { weeks }\end{array}$ \\
\hline Treatment & $\begin{array}{c}-0.0435^{* *} \\
(0.0196)\end{array}$ & $\begin{array}{c}0.0126 \\
(0.0218)\end{array}$ & $\begin{array}{c}0.752^{* *} \\
(0.0943)\end{array}$ & $\begin{array}{c}1.115 \\
(0.214)\end{array}$ \\
\hline Observations & 1772 & 1103 & 1772 & 1103 \\
\hline Wave FE & Yes & Yes & Yes & Yes \\
\hline $\begin{array}{l}\text { Pre-intervention } \\
\text { Mortality Control }\end{array}$ & Yes & Yes & Yes & Yes \\
\hline Model & OLS & OLS & Logistic & Logistic \\
\hline $\begin{array}{l}\text { Mean Dep. var. } \\
\text { (control-post) }\end{array}$ & .1448 & .1223 & .1448 & .1223 \\
\hline
\end{tabular}

Notes: The unit of observation is the child. The estimation method is OLS in columns 1 and 2, and logistic regression in columns 3 and 4. Note that coefficients below 1 represent a negative treatment effect in logistic regressions. Standard errors are clustered at the 'cluster' level. The sample is restricted to children born following the installation of chlorine dispensers. Treatment is an indicator variable that is equal to 1 for children from clusters where chlorine dispensers were installed and 0 otherwise. The outcome variable in columns 1 and 3 is an indicator for whether the child experienced a diarrheal episode in the past three months, which was collected at the John \& Orkin endline during surveys with enumerators. The outcome variable in columns 2 and 4 is an indicator for whether the child experienced a diarrheal episode in the past two weeks, which was collected at the John \& Orkin baseline (this explains the lower number of observations because the pure control group of John \& Orkin was not surveyed at baseline). Wave fixed effects are included in all columns. We condition on the cluster pre-intervention mortality rate in all columns. Standard errors in parentheses ${ }^{*} p<0.1,{ }^{* *} p<0.05,{ }^{* * *} p<0.01$.

Source: Authors' calculations, data by John \& Orkin (2018). 
Table A4: The effect of dilute chlorine solution provision on all-cause mortality - excluding children born after the John \& Orkin (2018) intervention to women in one of their treatment or placebo arms

\begin{tabular}{|c|c|c|c|c|c|c|}
\hline & (1) & (2) & (3) & (4) & (5) & (6) \\
\hline & $<2 y$ & $<2 y$ & $<2 y$ & $<5 y$ & $<5 y$ & $<5 y$ \\
\hline \multicolumn{7}{|c|}{ Panel A: Linear Probability Model } \\
\hline Treatment & $\begin{array}{l}-0.0122^{* *} \\
(0.00608)\end{array}$ & $\begin{array}{l}-0.0140^{* *} \\
(0.00616)\end{array}$ & $\begin{array}{c}0.00154 \\
(0.00599)\end{array}$ & $\begin{array}{l}-0.0147^{* *} \\
(0.00607)\end{array}$ & $\begin{array}{l}-0.0145^{* *} \\
(0.00596)\end{array}$ & $\begin{array}{l}-0.000840 \\
(0.00606)\end{array}$ \\
\hline \multirow{2}{*}{$\begin{array}{l}\text { Treatment x Post- } \\
\text { Intervention }\end{array}$} & & & $-0.0150^{* *}$ & & & $-0.0149^{* *}$ \\
\hline & & & $(0.00735)$ & & & $(0.00684)$ \\
\hline Post-Intervention & & & $\begin{array}{r}0.00949 \\
(0.00732) \\
\end{array}$ & & & $\begin{array}{r}0.00858 \\
(0.00688) \\
\end{array}$ \\
\hline \multicolumn{7}{|c|}{ Panel B: Odds Ratio Estimates } \\
\hline Treatment & $\begin{array}{c}0.371^{*} \\
(0.190)\end{array}$ & $\begin{array}{l}0.165^{* * *} \\
(0.0811)\end{array}$ & $\begin{array}{c}1.141 \\
(0.531)\end{array}$ & $\begin{array}{l}0.323^{* *} \\
(0.160)\end{array}$ & $\begin{array}{l}0.268^{* * *} \\
(0.0913)\end{array}$ & $\begin{array}{c}0.945 \\
(0.387)\end{array}$ \\
\hline \multirow{2}{*}{$\begin{array}{l}\text { Treatment x Post- } \\
\text { Intervention }\end{array}$} & & & $0.302^{* *}$ & & & $0.325^{* * *}$ \\
\hline & & & $(0.148)$ & & & $(0.135)$ \\
\hline Post-Intervention & & & $\begin{array}{c}1.867 \\
(0.746)\end{array}$ & & & $\begin{array}{c}1.624 \\
(0.600)\end{array}$ \\
\hline Observations & 1926 & 1926 & 3954 & 1926 & 1926 & 3954 \\
\hline Wave FE & Yes & Yes & Yes & Yes & Yes & Yes \\
\hline $\begin{array}{l}\text { Pre-intervention } \\
\text { Mortality Control }\end{array}$ & No & Yes & No & No & Yes & No \\
\hline $\begin{array}{l}\text { Mean Dep. var. } \\
\text { (control - post) }\end{array}$ & .0208 & .0208 & .0208 & .0229 & .0229 & .0229 \\
\hline
\end{tabular}

Notes: The unit of observation is the child. The estimation method is OLS in Panel A and logistic regression in Panel B. Note that coefficients below 1 represent a negative treatment effect in logistic regressions. Standard errors are clustered at the 'cluster' level. The sample excludes births after the John \& Orkin (2018) intervention to women in one of their treatment or placebo arms (i.e., it does include their pure control arm). Wave fixed effects are included in all columns. Treatment is an indicator variable that is equal to $1 \mathrm{for}$ children from clusters where chlorine dispensers were installed and 0 otherwise. Post is an indicator variable defined as 1 for the years following the installation of chlorine dispensers and 0 for the years before. We condition on the cluster pre-intervention mortality rate in columns 3 and 6. The sample is restricted to children born after the rollout of the WASH-B intervention in columns 1, 2, 4, and 5. All children are included in columns 3 and 6. Standard errors in parentheses ${ }^{*} p<0.1,{ }^{* *} p<0.05,{ }^{* * *} p<0.01$. Source: Authors' calculations, data by John \& Orkin (2018). 
Table A5: The effect of dilute chlorine solution provision on all-cause mortality - Heterogeneity across district and birth cohort

\begin{tabular}{|c|c|c|c|c|}
\hline & $\begin{array}{l}(1) \\
<5 y\end{array}$ & $\begin{array}{l}(2) \\
<5 y\end{array}$ & $\begin{array}{l}(3) \\
<5 y\end{array}$ & $\begin{array}{l}(4) \\
<5 y\end{array}$ \\
\hline Treatment & $\begin{array}{l}-0.0228^{* *} \\
(0.01059)\end{array}$ & $\begin{array}{l}-0.0217^{* *} \\
(0.01155)\end{array}$ & $\begin{array}{c}-0.0206 \\
(0.01330)\end{array}$ & $\begin{array}{c}-0.0194 \\
(0.01477)\end{array}$ \\
\hline Treatment $\mathrm{x}$ District $=$ Bungoma Central & $\begin{array}{c}0.0113 \\
(0.01364)\end{array}$ & $\begin{array}{c}0.0088 \\
(0.01452)\end{array}$ & & \\
\hline Treatment $\mathrm{x}$ District $=$ Matungu & $\begin{array}{c}0.0116 \\
(0.013645)\end{array}$ & $\begin{array}{c}0.0113 \\
(0.01415)\end{array}$ & & \\
\hline Treatment $\mathrm{x}$ District $=$ Mumias & $\begin{array}{c}0.0294^{* *} \\
(0.013861)\end{array}$ & $\begin{array}{c}0.0311^{* *} \\
(0.016724)\end{array}$ & & \\
\hline Treatment $\mathrm{x}$ Birth Year $=2015$ & & & $\begin{array}{c}0.0158 \\
(0.01981)\end{array}$ & $\begin{array}{c}0.0144 \\
(0.02004)\end{array}$ \\
\hline Treatment $\mathrm{x}$ Birth Year $=2016$ & & & $\begin{array}{c}0.0064 \\
(0.01833)\end{array}$ & $\begin{array}{c}0.0026 \\
(0.01954)\end{array}$ \\
\hline Treatment $\mathrm{x}$ Birth Year $=2017$ & & & $\begin{array}{c}0.0025 \\
(0.01446)\end{array}$ & $\begin{array}{c}0.0036 \\
(0.01587)\end{array}$ \\
\hline Treatment $\mathrm{x}$ Birth Year $=2018$ & & & $\begin{array}{c}0.0243 \\
(0.01633)\end{array}$ & $\begin{array}{c}0.0217 \\
(0.01848)\end{array}$ \\
\hline Observations & 1926 & 1926 & 1926 & 1926 \\
\hline Wave FE & Yes & Yes & Yes & Yes \\
\hline District FE & Yes & Yes & Yes & Yes \\
\hline Pre-intervention Mortality Control & No & Yes & No & Yes \\
\hline Mean Dep. var. (control - post) & 0223 & 0223 & .0223 & .0223 \\
\hline
\end{tabular}

Notes: The unit of observation is the child. The estimation method is OLS. Standard errors are clustered at the 'cluster' level. Treatment is an indicator variable that is equal to 1 for children from clusters where chlorine dispensers were installed and 0 otherwise. Wave fixed effects are included in all columns. We condition on the cluster pre-intervention mortality rate in columns 2 and 4 . The sample is restricted to children born after the rollout of the WASH-B intervention, and before the John \& Orkin intervention. The omitted interaction variable is "District = Bumula" in column 1 and 2. Standard errors in parentheses ${ }^{*} p<0.1,{ }^{* *} p<0.05,{ }^{* * *} p<0.01$.

Source: Authors' calculations, data by John \& Orkin 
Table A6: The effect of dilute chlorine solution provision on health behavior

\begin{tabular}{|c|c|c|c|c|c|c|}
\hline & Outcome Variable & Treatment & Std. Error & $\begin{array}{l}\text { FDR q- } \\
\text { value }\end{array}$ & Obs. & $\begin{array}{l}\text { Mean Dep. } \\
\text { Var. (control) }\end{array}$ \\
\hline$(1)$ & Proportion of children $\mathrm{u} 15$ vaccinated in last 3 months & -0.0317 & $(0.0205)$ & 1.000 & 2014 & .253 \\
\hline$(2)$ & Washes hands: After Toilet & 0.00332 & $(0.0188)$ & 1.000 & 1833 & .882 \\
\hline$(3)$ & Washes hands: Before Eating & -0.0799 & $(0.0342)^{\text {** }}$ & 0.339 & 1833 & .809 \\
\hline$(4)$ & Washes hands: After Eating & -0.0483 & $(0.0497)$ & 1.000 & 1833 & .61 \\
\hline$(5)$ & Washes hands: Before Cooking/Preparing Food & -0.0661 & $(0.0461)$ & 1.000 & 1833 & .476 \\
\hline$(6)$ & Washes hands: After Cleaning Baby's Backside & -0.0388 & $(0.0334)$ & 1.000 & 1833 & .198 \\
\hline$(7)$ & Washes hands: Before feeding baby & -0.0533 & $(0.0306)^{*}$ & 1.000 & 1833 & .217 \\
\hline$(8)$ & Washes hands: After Farmwork/Working Outside & 0.0647 & $(0.0279)^{* *}$ & 0.339 & 1833 & .481 \\
\hline$(9)$ & Washes hands: After Picking Up Rubbish & 0.0125 & $(0.0335)$ & 1.000 & 1833 & .428 \\
\hline$(10)$ & Washes hands: After Handling Animals & -0.0145 & $(0.0220)$ & 1.000 & 1833 & .094 \\
\hline$(11)$ & Washes hands: After Greeting Someone & 0.00585 & $(0.0256)$ & 1.000 & 1833 & .346 \\
\hline$(12)$ & Washes hands: After the Market & 0.00564 & $(0.0251)$ & 1.000 & 1833 & .237 \\
\hline$(13)$ & Washes hands: After Travelling & 0.0435 & $(0.0289)$ & 1.000 & 1833 & .243 \\
\hline$(14)$ & Washes hands: Does not wash hands regularly & 0.000954 & $(0.00156)$ & 1.000 & 1833 & .001 \\
\hline$(15)$ & Washes hands: Other & -0.00174 & $(0.0114)$ & 1.000 & 1833 & .018 \\
\hline$(16)$ & Available for handwashing: Soap & -0.00809 & $(0.00713)$ & 1.000 & 1837 & .983 \\
\hline$(17)$ & Available for handwashing: Detergent & -0.0283 & $(0.0260)$ & 1.000 & 1837 & .179 \\
\hline$(18)$ & Available for handwashing: Ash/Mud/Sand & 0.0110 & $(0.0101)$ & 1.000 & 1837 & .016 \\
\hline (19) & Available for handwashing: None & 0.00321 & $(0.00299)$ & 1.000 & 1837 & .002 \\
\hline (20) & $\begin{array}{l}\text { How often do you wash fresh fruit and vegetables } \\
\text { before eating? }\end{array}$ & -0.0266 & $(0.0832)$ & 1.000 & 1833 & 3.639 \\
\hline (21) & $\begin{array}{l}\text { Proportion of children taken for healthcare check-up in } \\
\text { last } 3 \text { months }\end{array}$ & 0.0148 & $(0.0245)$ & 1.000 & 1837 & .323 \\
\hline$(22)$ & Always Washes Fruit Dummy & -0.00529 & $(0.0414)$ & 1.000 & 1838 & .788 \\
\hline
\end{tabular}


Notes: The unit of observation is the mother. The estimation method is OLS. Standard errors are clustered at the 'cluster' level. Treatment is an indicator variable that is equal to 1 for children from clusters where chlorine dispensers were installed and 0 otherwise. Wave fixed effects are included in all columns. Standard errors in parentheses. We use False Discovery Rate (FDR) q-values for multiple hypothesis testing. ${ }^{*} p<0.1,{ }^{* *} p<0.05,{ }^{* * *} p<0.01$. 


\section{Table A7: Relevant Questions from Surveys}

\begin{tabular}{lll}
\hline & Question & Choices \\
\hline$\underline{\text { A. Baseline }}$ &
\end{tabular}

What is your marital status?

What is the highest stage of school you completed?
1 I am married or live with my partner

I have a partner but we don't live

2 together

3 I am single or widowed

$0 \quad$ None

1 Pre-school

2 Standard 1

$3 \quad$ Standard 2

$4 \quad$ Standard 3

$5 \quad$ Standard 4

$6 \quad$ Standard 5

$7 \quad$ Standard 6

$8 \quad$ Standard 7

$9 \quad$ Standard 8

$10 \quad$ Form 1

11 Form 2

$12 \quad$ Form 3

13 Form 4

14 Form 5

$15 \quad$ Form 6

16 Vocational 1

$17 \quad$ Vocational 2

$18 \quad$ Vocational 3

19 College 1

$20 \quad$ College 2

$21 \quad$ College 3

$22 \quad$ College 4

23 University 1

24 University 2 
What is your primary occupation?

What is the floor in your house made of?

Do you own your house?

Do you own the plot of land that your home is on?

Which of these items does your household own?

7

8

9

10

1

$\begin{array}{ll}11 & \text { Watch or Clock } \\ \text { none } & \text { None of the above }\end{array}$

How many cooking items (frying pans, pots, etc.) does your household own?
0

0

University 3

University 4

University $5+$

I have no work at all

I work for somebody else's business

I work for my own business

I farm to provide for my family

Other

1 Earth or Mud

2 Grass

3 Wood or Sticks

4 Iron sheets

$5 \quad$ Tiles

6 Bricks or Stones

Plaster or Cement

-77 Other

1 Yes

$0 \quad$ No

$1 \quad$ Yes

$0 \quad$ No

1 Refrigerator

2 Radio

3 Television (black and white or colour)

Any kind of Telephone

5 Bicycle

6 Motorbike/ Scooter

$7 \quad$ Car

$8 \quad$ Truck

9 Iron box (charcoal or electric)

10 Solar panels

$0 \quad$ None 
Where did you get the chlorine from?

How often do you treat your water before drinking it?

Did you put chlorine in your water in the last month?

Where did you get the chlorine from?

Has $\$\{$ hhd_name $\}$ had diarrhea in the last two weeks?
$1 \quad$ One

2

$3 \quad$ Piped into plot/yard

4

6 Stream

$7 \quad$ Lake/pond

$8 \quad$ Roof water

$9 \quad$ Catchment tank

10 Delivered by truck

-777 Other

$1 \quad$ Never

2 Occasionally

3 Most of the time

$4 \quad$ Always

$1 \quad$ Yes

$0 \quad$ No

1 I bought a bottle at the store

2 I borrowed from a neighbour's bottle

3 I was given a bottle for free

$4 \quad$ From the dispenser at the water source

-777 Other

$1 \quad$ Yes

$0 \quad$ No

\section{$\underline{\text { B. Endline In-Person Survey }}$}

In the last 10 years, how many times in total have you been pregnant? As a reference, these would be pregnancies that happened after the Kenyan Presidential elections of December, 2007. Please count all pregnancies regardless of whether they resulted in a live birth 
In the last 10 years, how many of these pregnancies resulted in a live birth?

$\begin{array}{ll}\text { Integer } & \\ \text { Integer } & \\ \text { Text } & \\ \text { Integer } & \\ 1 & \text { Yes } \\ 0 & \text { No }\end{array}$

How many of these children have been vaccinated in the last three months?

Integer

How many of these children have visited a health care provider in the past 3 months even when they were not ill for preventative care or for a check-up?

Integer

You said that you gave birth to $\$\{q 3\}$ children in the last ten years but told us about $\$\left\{q 3 \_\right.$live $\}$who are still alive. Did you lose $\$\{$ death_vs_living $\}$ children?

$\begin{array}{ll}1 & \text { Yes } \\ 0 & \text { No }\end{array}$

Could you tell me the name of the Child $\$\left\{\mathrm{dr} \_\right.$index $\}$who died? Text

How old was $\$\{\mathrm{q} 32\}$ when they died in years?

$\begin{array}{ll}0 & 0 \text { (ie. less than One Year Old) } \\ 1 & 1 \\ 2 & 2 \\ 3 & 3 \\ 4 & 4 \\ 5 & 5 \\ 6 & 6 \\ 7 & 7 \\ 8 & 8 \\ 9 & 9 \\ 10 & 10 \\ -100 & \text { Don't understand } \\ -88 & \text { Not applicable } \\ -98 & \text { Refused } \\ -99 & \text { Don't know }\end{array}$

$\begin{array}{ll}\text { Could you tell me the month and year of } \$\{\mathrm{q} 32\} \text { birth? } & \text { Date } \\ \text { Could you tell me the month and year of } \$\{\mathrm{q} 32\} \text { death? } & \text { Date }\end{array}$ 


\section{Endline Phone Survey}

When do you wash your hands? Any other time?

$\begin{array}{ll}1 & \text { After toilet } \\ 2 & \text { Before eating } \\ 3 & \text { After eating } \\ 4 & \text { Before cooking/preparing food } \\ 5 & \text { After cleaning baby's backside } \\ 6 & \text { Before feeding baby } \\ 7 & \text { After farmwork/working outside } \\ 8 & \text { After picking up rubbish/handling dirty } \\ 9 & \text { Afings } \\ 10 & \text { After handling animals } \\ 11 & \text { After coming back from the market } \\ 12 & \text { After travelling } \\ 13 & \text { None/don't wash hands regularly } \\ -222 & \text { Other }\end{array}$

Currently are any of the following available in your house or yard for members of your household to use to wash their hands?

$\begin{array}{lll} & 2 & \text { Detergent } \\ & 3 & \text { Ash/mud/sand } \\ \text { How often do you wash fresh fruit and vegetables before eating? } & 1 & \text { None } \\ & 2 & \text { Occasionally } \\ & 3 & \text { Most of the time } \\ & 4 & \text { Always }\end{array}$

